\title{
A Magnetocaloric Pump for Lab-On-A- Chip Technology: Phase I Report
}

\section{October 2003}

Prepared by

L. J. Love

J. F. Jansen

T. E. McKnight

T. J. Phelps

Y. Roh 


\section{DOCUMENT AVAILABILITY}

Reports produced after January 1, 1996, are generally available free via the U.S. Department of Energy (DOE) Information Bridge:

Web site: http://www.osti.gov/bridge

Reports produced before January 1, 1996, may be purchased by members of the public from the following source:

National Technical Information Service

5285 Port Royal Road

Springfield, VA 22161

Telephone: 703-605-6000 (1-800-553-6847)

TDD: $703-487-4639$

Fax: 703-605-6900

E-mail: info@ntis.fedworld.gov

Web site: http://www.ntis.gov/support/ordernowabout.htm

Reports are available to DOE employees, DOE contractors, Energy Technology Data Exchange (ETDE) representatives, and International Nuclear Information System (INIS) representatives from the following source:

Office of Scientific and Technical Information

P.O. Box 62

Oak Ridge, TN 37831

Telephone: 865-576-8401

Fax: 865-576-5728

E-mail: reports@adonis.osti.gov

Web site: http://www.osti.gov/contact.html

This report was prepared as an account of work sponsored by an agency of the United States Government. Neither the United States government nor any agency thereof, nor any of their employees, makes any warranty, express or implied, or assumes any legal liability or responsibility for the accuracy, completeness, or usefulness of any information, apparatus, product, or process disclosed, or represents that its use would not infringe privately owned rights. Reference herein to any specific commercial product, process, or service by trade name, trademark, manufacturer, or otherwise, does not necessarily constitute or imply its endorsement, recommendation, or favoring by the United States Government or any agency thereof. The views and opinions of authors expressed herein do not necessarily state or reflect those of the United States Government or any agency thereof. 
ORNL-2003/245

\title{
A MAGNETOCALORIC PUMP FOR LAB-ON-A-CHIP TECHNOLOGY：PHASE I REPORT
}

\author{
L. J. Love, J. F. Jansen, T. E. McKnight, T. J. Phelps, Y. Roh
}

Date Published: October 2003

\author{
Prepared by \\ OAK RIDGE NATIONAL LABORATORY \\ P.O. Box 2008 \\ Oak Ridge, Tennessee 37831-6285 \\ managed by \\ UT-Battelle, LLC \\ for the \\ U.S. DEPARTMENT OF ENERGY \\ under contract DE-AC05-00OR22725
}





\section{TABLE OF CONTENTS}

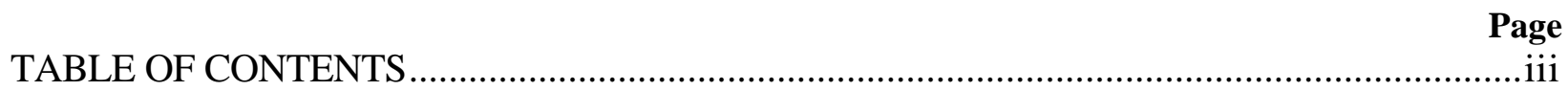

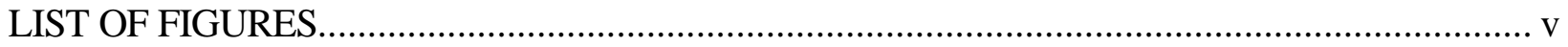

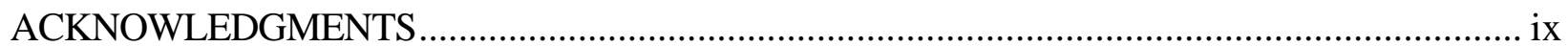

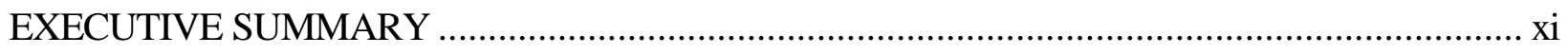

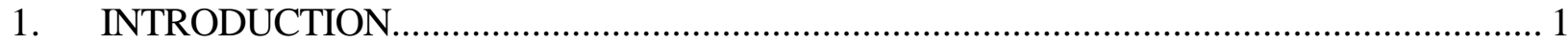

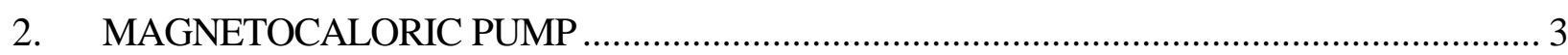

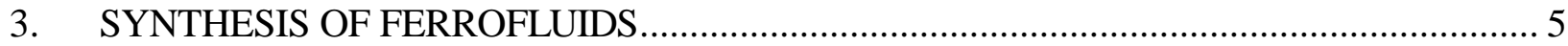

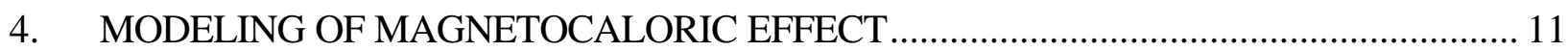

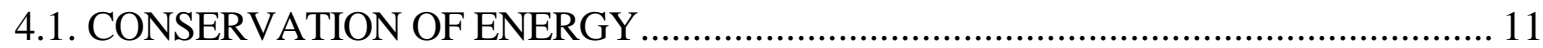

4.2. MAGNETIC PRESSURE …………………………….......................................... 11

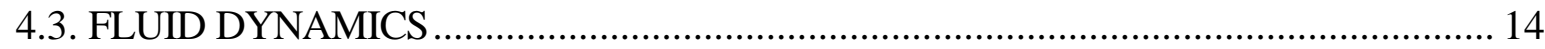

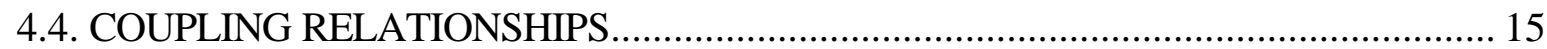

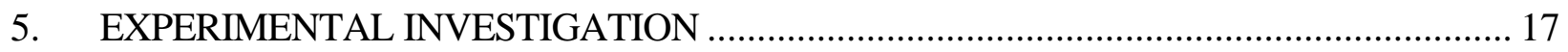

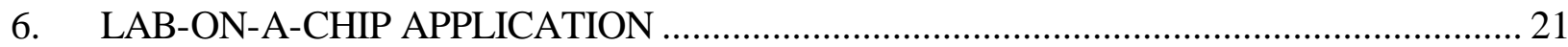

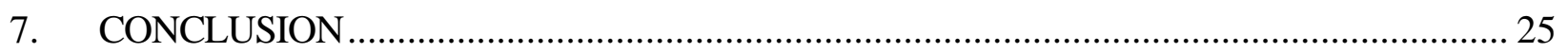

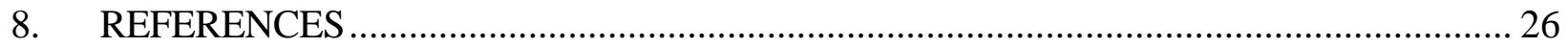





\section{LIST OF FIGURES}

Figure

Page

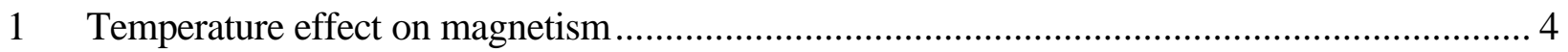

2 Field effect on ferrofluid ........................................................................................ 4

3 Proof-of-principle ferrofluid pump ........................................................................... 4

4 X-ray diffraction analysis of magnetite formed by thermophilic metal-reducing bacteria using iron oxyhydroxide (akaganeite) as a magnetite precursor (A). Thermophilic metal-reducing bacteria formed magnetite nanoparticles using akaganeite as an electron acceptor and

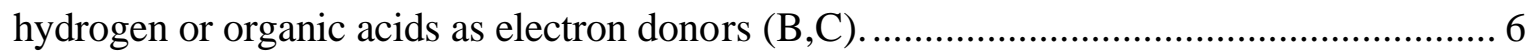

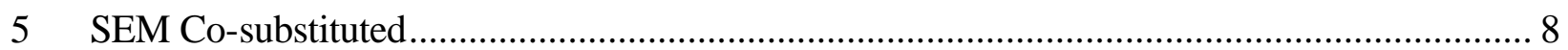

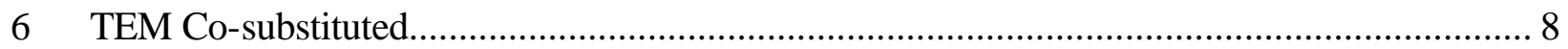

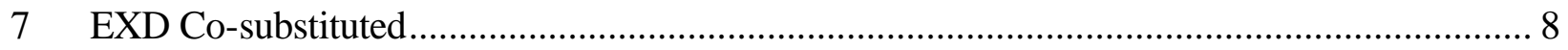

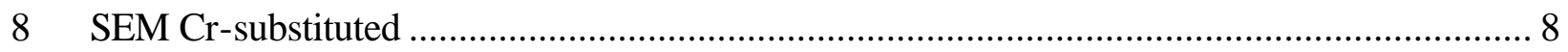

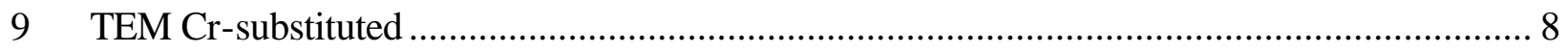

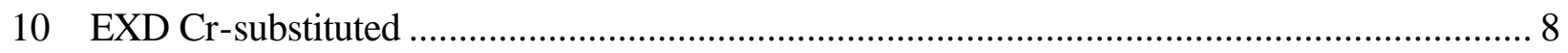

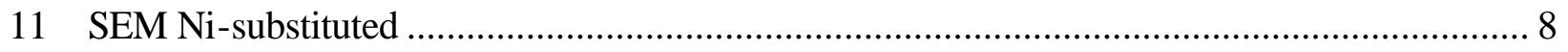

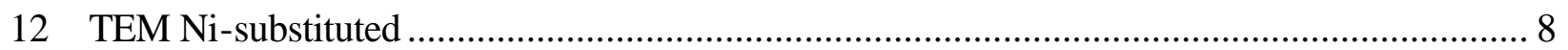

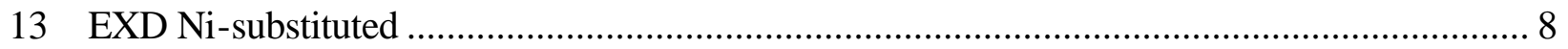

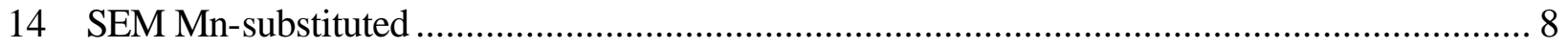

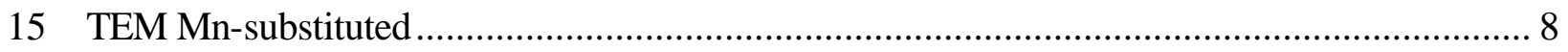

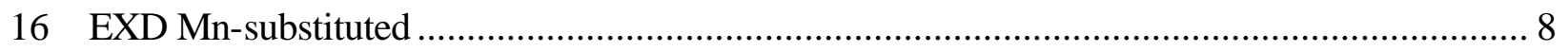

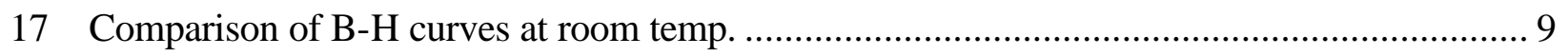

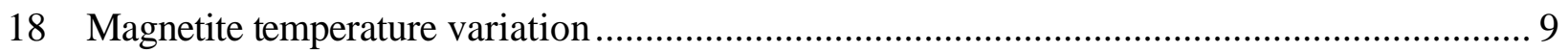





\section{LIST OF FIGURES (cont'd)}

Figure

Page

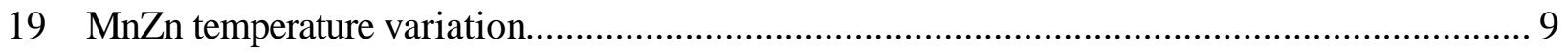

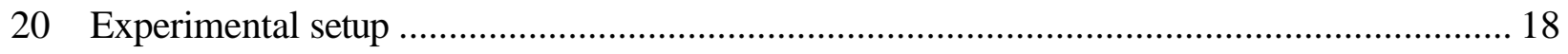

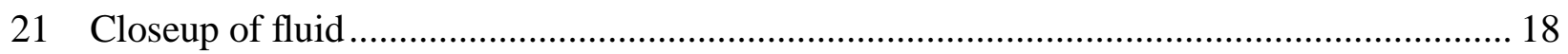

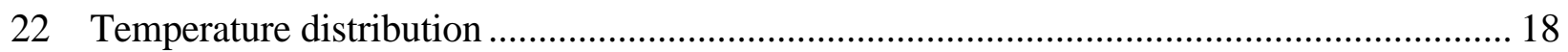

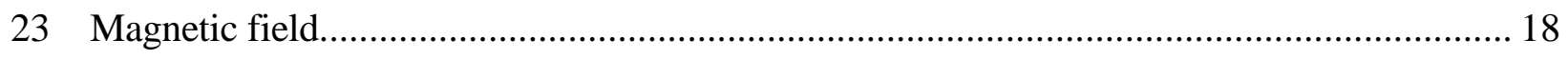

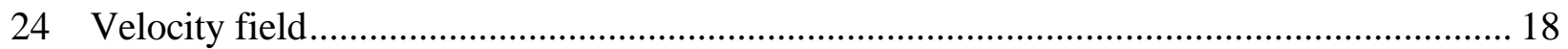

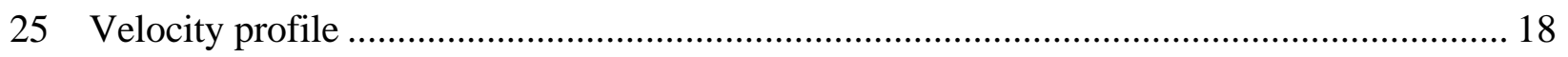

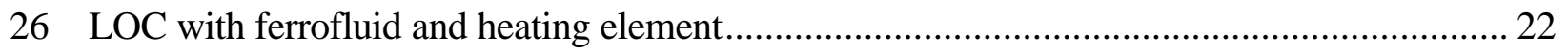

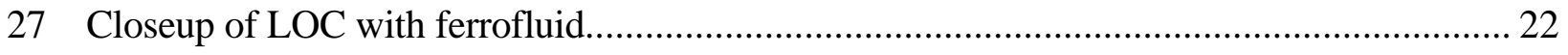

28 Oil based Mn-Zn ferrofluid in LOC ...................................................................... 22

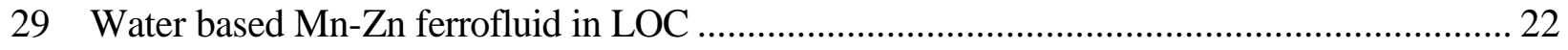

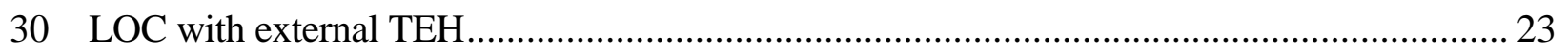

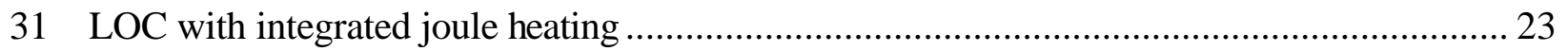

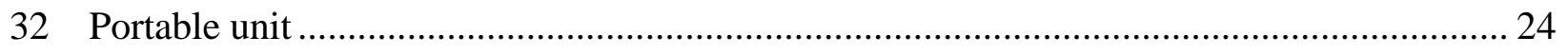

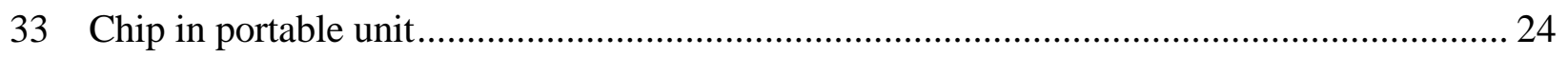





\section{ACKNOWLEDGMENTS}

The authors would like to thank Dr. Valerie Browning of the Defense Advanced Research Projects Agency (DARPA). First, it was Dr. Browning who provided the original inspiration for using the magnetocaloric energy conversion on the lab-on-a-chip technology. Second, this work was funded by Dr. Browning under the BioMagnetICs Program. 



\section{EXECUTIVE SUMMARY}

A magnetocaloric pump provides a simple means of pumping fluid using only external thermal and magnetic fields. The principle, which can be traced back to the early work of Rosensweig, is straightforward. Magnetic materials tend to lose their magnetization as the temperature approaches the material's Curie point. Exposing a column of magnetic fluid to a uniform magnetic field coincident with a temperature gradient produces a pressure gradient in the magnetic fluid. As the fluid heats up, it loses its attraction to the magnetic field and is displaced by cooler fluid. The impact of such a phenomenon is obvious: fluid propulsion with no moving mechanical parts. Until recently, limitations in the magnetic and thermal properties of conventional materials severely limited practical operating pressure gradients. However, recent advancements in the design of metal substituted magnetite enable fine control over both the magnetic and thermal properties of magnetic nanoparticles, a key element in colloidal based magnetic fluids (ferrofluids). This manuscript begins with a basic description of the process and previous limitations due to material properties. This is followed by a review of existing methods of synthesizing magnetic nanoparticles as well as an introduction to a new approach based on thermophilic metal-reducing bacteria. We compare two compounds and show, experimentally, significant variation in specific magnetic and thermal properties. We develop the constitutive thermal, magnetic, and fluid dynamic equations associated with magnetocaloric pump and validate our finite element model with a series of experiments. Preliminary results show a good match between the model and experiment as well as approximately an order of magnitude increase in the fluid flow rate over conventional magnetite based ferrofluids operating below $80^{\circ} \mathrm{C}$. Finally, as a practical demonstration, we describe a novel application of this technology: pumping fluids at the "Lab-on-aChip" (LOC) microfluidic scale. The potential payoff to DOE and DoD is a new approach, requiring low voltage and low current, for pumping fluid at the LOC scale. 



\section{INTRODUCTION}

Ferrofluids are oil-based liquids that are loaded with nanometer sized ferrous particles. Magnetorheological fluids (MR) are similar in structure, but differ in their behavior. MR fluids are oils loaded with micron sized soft magnetic particles. The volumetric particle loading is generally from 20 to $40 \%$. To prevent agglomeration, a surfactant (generally oleic acid) is added to modify the surface of the particles. When exposed to a magnetic field, the fluid exhibits very large variations in viscosity. The behavior of the particles and fluid is such that large variations in viscosity can occur and be controlled very rapidly, transitioning from a light viscous fluid to a thick consistency in a few milliseconds. However, the particle size is large enough that separation and settling of the particles from the fluid occurs over time and during exposure to intense magnetic fields. While there are many similarities between the structure of MR and ferrofluids, the slight differences play a very significant role in the fluid's behavior. Like MR fluids, ferrofluids are fluids loaded with small magnetic particles coated with a surfactant. The fundamental differences are the particle size (generally in the 10 to 50 nanometer range) and volumetric loading (from 5 to $10 \%$ ). The particle size plays a significant role in the particle's magnetic behavior as well as in the mechanical behavior of the particles in the fluid. In terms of the magnetic characteristics, ferrofluid particles are generally small enough to exhibit a single magnetic domain. Subsequently no magnetic work is required to shift magnetic domains in the material (i.e. no hysteresis). As far as the mechanical behavior, unlike MR fluids, ferrofluids remain in suspension, even during extended exposure to magnetic fields. Thermal agitation in the fluid, even at room temperature, exceeds the gravitational potential of the particles. The lower loading percentage and particle size yields a fluid attracted to a magnetic field with much lower variations in the viscosity of the fluid. Subsequently, it should be clear that while the structure of MR and ferrofluids is similar, their behavior, and subsequent applications, are dramatically different.

There are presently many applications using ferrofluids. Nethe is using a new ferrofluid-driven actuator for a ventricular assist device. ${ }^{1}$ Recent biological applications focus on using ferrofluids for cell separation. ${ }^{2}$ A survey of commercial applications includes galvonometers and inclinometers that exploit the levitation characteristics of the fluid as well as environmental seals and voice coil actuators exploiting the fluid's magnetic attraction. ${ }^{3}$ Stepper motors experience a high frequency oscillation during slewing maneuvers. ${ }^{4}$ Ferrofluids in the air gap of stepper motors provide an efficient means to damp this vibration. ${ }^{5}$ The field in the gap naturally retains the fluid against forces of acceleration, shock, and vibration. However, care must be taken in the selection of the ferrous particles for this application. If the temperature in the gap approaches the Curie temperature of the particles, the fluid will no longer be attracted to the field. It is this limitation that we will exploit for field induced ferrofluid propulsion. The emphasis of this paper is on describing the behavior of this fluid, specifically the thermal-magnetic behavior, characterize the critical components of the particles and fluid that impact energy conversion, describe existing synthesis and analysis methodologies and will end with a series of experiments and a survey of potential applications. 



\section{MAGNETOCALORIC PUMP}

A magnetocaloric pump provides a simple means of pumping fluid using only external thermal and magnetic fields. The principle, which can be traced back to the early work of Rosensweig, is straightforward. ${ }^{6}$ Magnetic materials tend to lose their magnetization as the temperature approaches the material's Curie point. Exposing a column of magnetic fluid to a uniform magnetic field coincident with a temperature gradient produces a pressure gradient in the magnetic fluid. As the fluid heats up, it loses its attraction to the magnetic field and is displaced by cooler fluid. In order to achieve magnetocaloric pumping, we must first understand the temperature dependence of magnetic materials. Magnetization of materials is based upon alignment of the magnetic moments of individual atoms. Ferromagnetic materials contain domains in the material where there is consistent alignment of the magnetic moments. When exposed to an external magnetic field, these domains grow, increasing the net magnetization (M) of the material. However, sufficient thermal agitation disrupts the alignment of magnetic moments, reducing the net magnetization. Fig. 1 shows the degradation in magnetization as a function of temperature. The temperature at which all net magnetization is lost is called the Curie temperature, $T_{c}$. This temperature is a function of the atomic density, $\mathrm{m}$, material magnetic dipole moment, $\mu_{\mathrm{m}}$, permeability of air, $\mu_{\mathrm{o}}$, and Boltzmann's constant, $\mathrm{k}$. Table 1 lists the saturation magnetization and Curie temperature of a variety of known magnetic materials.

$$
\begin{aligned}
\mathrm{T}_{\mathrm{c}} & =\frac{\mathrm{m} \mu_{0} \mu_{\mathrm{m}}^{2}}{3 \mathrm{k}} \\
\mathrm{M} & =\mathrm{m} \mu_{\mathrm{m}}
\end{aligned}
$$

Table 1. Curie temperature and saturation magnetization of ferromagnetic solids.

\begin{tabular}{||c|c|c||}
\hline Substance & Curie Temp $\left.{ }^{\circ} \mathbf{C}\right)$ & $\mu_{0} \mathbf{M}_{\mathbf{s}}(\mathbf{T})$ \\
\hline Dysprosium & -185 & 3.67 \\
\hline Gadolinium & 19 & 2.59 \\
\hline Nickel & 358 & 0.64 \\
\hline Magnetite & 585 & 0.56 \\
\hline Iron & 770 & 2.18 \\
\hline Cobalt & 1120 & 1.82 \\
\hline
\end{tabular}

Ferrofluids are based on magnetic nanoparticles that are so small that they contain only a single magnetic domain. While temperature may not disrupt the magnetic domain in the particles, it can disrupt any alignment between adjacent particles. Thus, ferrofluids experience a similar demagnetization as a function of temperature. Magnetocaloric energy conversion was first described by Rosenswieg. ${ }^{6}$ The principle of operation, shown in Figs. 1 and 2, is relatively simple. The ferrofluid is attracted to the magnetic field (in this case, from a coil or permanent magnet). As the fluid enters the thermal field, the temperature of the fluid and nanoparticles increases. As the temperature approaches the Curie temperature, the material's local magnetization decreases. Cooler fluid, which is attracted to the magnetic field, displaces the warmer fluid and the result is fluid flow using only external magnetic and thermal fields. 


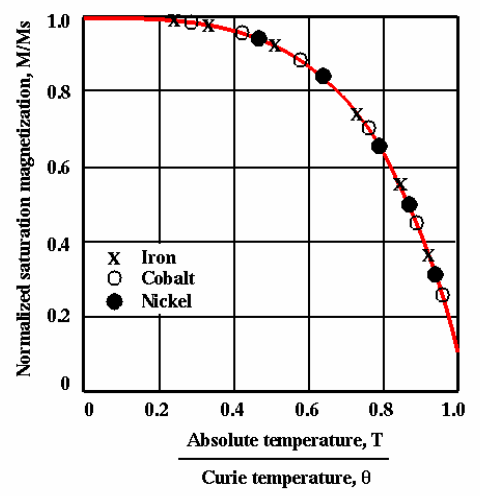

Fig. 1. Temperature effect on magnetism.

Figure 3 shows a working prototype of this pumping mechanism. The ideal particle would have a Curie temperature close to the maximum system operating temperature. Table 1 lists the Curie temperature of a number of ferrous materials. Most commercial grade ferrofluids are based on magnetite particles. While initially attractive from a fabrication perspective (cost), the Curie temperature of magnetite particles is far above the expected operating temperature of many conventional fluidic systems. Most fluids would boil before the temperature would significantly reduce the material's magnetization.

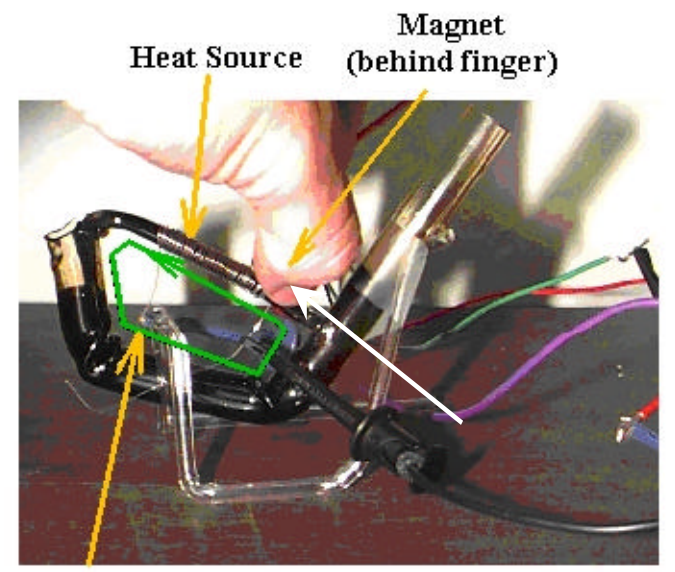

Fluid Circulation

Fig. 3. Proof-of-principle ferrofluid pump. 


\section{SYNTHESIS OF FERROFLUIDS}

There are many approaches to the synthesis of magnetic nanoparticles such as size reduction through ball milling, chemical precipitation, and microbial synthesis. Ball milling was the earliest approach to the synthesis of particles for ferrofluids. Micron-sized particles are submitted to a ball grinding process for approximately 1000 hours. While easy to operate, this methodology is costly and difficult to control and wustite is also expected to be formed during the milling of mixtures of Fe and $\mathrm{Fe}_{2} \mathrm{O}_{3}$. Synthesis by chemical precipitation is the more common approach in which the particles precipitate out of solution during chemical processes. ${ }^{7}$ A new approach, developed at Oak Ridge National Laboratory (ORNL), is based upon microbial synthesis that metal-reducing bacteria reduce iron oxyhydroxides to nanometer-sized magnetic iron oxides. ${ }^{8}$ The thermophilic metal-reducing bacteria under investigation at ORNL have demonstrated an ability to reduce a number of different metal ions. As with the milling and chemical precipitation processes, it is possible to incorporate other metals ( $\mathrm{Mn}(\mathrm{II}), \mathrm{Co}(\mathrm{II}), \mathrm{Ni}(\mathrm{II})$, and $\mathrm{Cr}(\mathrm{III})$ ) into magnetite $\left(\mathrm{Fe}_{3} \mathrm{O}_{4}\right)$ structure to control magnetic, electrical, and physical properties of the substituted magnetite. ${ }^{9}$ While the understanding of the actual process is still under investigation, magnetic nanoparticles are formed and shed on the skin of the bacteria as they move through iron oxyhydroxides plus soluble metal species, as illustrated in Fig. 4B. Microbial synthesis of magnetite was performed using akaganeite $(\mathrm{B}-\mathrm{FeOOH})$ as a magnetite precursor. The akaganeite was prepared as follows: $\mathrm{NaOH}$ solution $(10 \mathrm{M})$ was slowly added into a $\mathrm{FeCl}_{2} \cdot 6 \mathrm{H}_{2} \mathrm{O}$ solution $(0.4 \mathrm{M})$ to precipitate $\mathrm{Fe}(\mathrm{OH})_{2}$ by gravity only and with rapid stirring at $\mathrm{pH}$ 7.0. ${ }^{10}$ The suspension was aerated overnight by magnetic stirring, ensuring homogeneous oxidation. $\mathrm{X}$ ray diffraction analysis showed that the magnetite precursor was mainly poorly crystalline akaganeite (ß-FeOOH) (Fig. 4A and B). X-ray diffraction pattern of the magnetite precursor matched with those for akaganeite from Powder Diffraction File data card \#34-1266. ${ }^{11}$ After three days of incubation with akaganeite and thermophilic Fe(III)-reducing bacteria, the reddish colored akaganeite became completely black and magnetic. X-ray diffraction analyses of iron minerals formed was comprised of magnetite (Fig. 4A and C) that matched with those for magnetite from Powder Diffraction File data card \#6-696. This approach to particle synthesis is attractive from many vantage points. First, particle size and morphology are very consistent since the process occurs on the surface of the bacteria. The process is extremely scalable. Researchers at ORNL have observed little change in efficiency from $20 \mathrm{ml}$ to $20 \mathrm{~L}$ batches. Production rate is approximately $10,000 \mathrm{~s} \mathrm{mg}$ of magnetite/gallon of culture per day. Furthermore, in a culture, the bacteria replicate approximately once every three hours. ${ }^{12}$ 

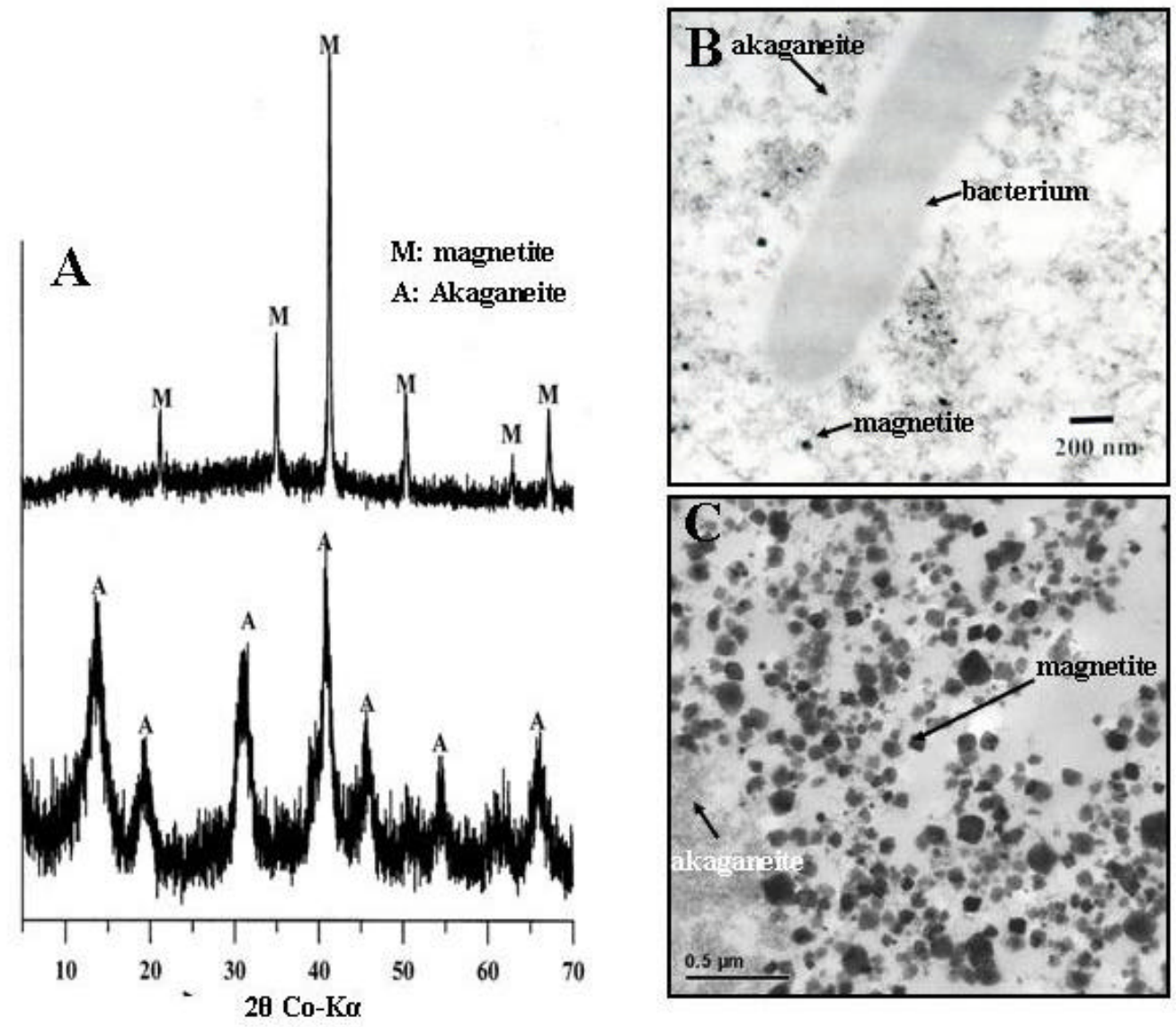

Fig. 4. X-ray diffraction analysis of magnetite formed by thermophilic metal-reducing bacteria using iron oxyhydroxide (akaganeite) as a magnetite precursor (A). Thermophilic metal-reducing bacteria formed magnetite nanoparticles using akaganeite as an electron acceptor and hydrogen or organic acids as electron donors $(\mathrm{B}, \mathrm{C})$.

During the first phase of this effort, we conducted a preliminary investigation of the potential for biologically synthesizing ferrofluids. There were two primary points of interest. First was the ability to control particle size. Our investigation concluded that crystal size is controlled by temperature. A summary of our results is listed in Table 2. Second, we explored the potential for synthesizing metal substituted magnetite biologically. Our preliminary investigation concluded that the thermophilic and psychrotolerant bacteria can synthesize a wide range of metal substituted magnetites. Our preliminary findings our summarized in Table 3. Figs. 5 through 16 display SEM, TEM and EXD's of a sampling of the materials. 
Table 2 : Crystal size as a function of growth condition

\begin{tabular}{|l|l|l|l|l|}
\hline Organism & Growth condition & $\begin{array}{l}\text { Growth and } \\
\text { mineralization rate }\end{array}$ & $\begin{array}{l}\text { Compositions } \\
\text { of biogenic magnetite }\end{array}$ & $\begin{array}{l}\text { Crystal size of } \\
\text { biogenic } \\
\text { magnetite }\end{array}$ \\
\hline $\begin{array}{l}\text { Shewannella } \\
(\mathrm{NV}-1, \mathrm{~W} 3-6-1, \mathrm{~W} 3-7-1)\end{array}$ & $\begin{array}{l}\text { Psychrotolerant } \\
\left(0-37^{\circ} \mathrm{C}\right)\end{array}$ & $1-2$ weeks & $\begin{array}{l}\text { Fe3O4 }\left(4-14^{\circ} \mathrm{C}\right) \\
\mathrm{Fe} 3 \mathrm{O} 4\left(14-37^{\circ} \mathrm{C}\right)\end{array}$ & $\begin{array}{l}10-30 \mathrm{~nm} \\
30-70 \mathrm{~nm}\end{array}$ \\
\hline $\begin{array}{l}\text { Thermoanaerobacter (TOR-39, } \\
\mathrm{C} 1, \mathrm{X} 513, \mathrm{X} 514, \mathrm{X} 561)\end{array}$ & $\begin{array}{l}\text { Thermophilic } \\
\left(40-70^{\circ} \mathrm{C}\right)\end{array}$ & $1-3$ days & $\begin{array}{l}\mathrm{Fe} 3 \mathrm{O} 4(<16 \mathrm{~h} \\
\left.\text { incubation, } 65^{\circ} \mathrm{C}\right)\end{array}$ & $\begin{array}{l}30-70 \mathrm{~nm} \\
\text { Fe3O4 }(>24 \mathrm{~h} \\
\left.\text { incubation, } 65^{\circ} \mathrm{C}\right)\end{array}$ \\
\hline
\end{tabular}

Table 3: Bio-synthesized metal substituted magnetite

\begin{tabular}{|l|l|l|l|l|}
\hline Organism & Growth condition & $\begin{array}{l}\text { Growth and } \\
\text { mineralization } \\
\text { rate }\end{array}$ & $\begin{array}{l}\text { Compositions } \\
\text { of biogenic magnetite }\end{array}$ & $\begin{array}{l}\text { Crystal size of } \\
\text { biogenic } \\
\text { magnetite }\end{array}$ \\
\hline $\begin{array}{l}\text { Thermoanaerobacter (TOR-39, } \\
\mathrm{C} 1, \mathrm{X} 513, \mathrm{X} 514, \mathrm{X} 561) \\
\left(40-70^{\circ} \mathrm{C}\right)\end{array}$ & $1-3$ days & $\begin{array}{l}\mathrm{Fe} 3-\mathrm{xCoxO} 4, \mathrm{Fe} 3-\mathrm{xCrxO} 4 \\
\mathrm{Fe} 3-\mathrm{xNixO} 4, \mathrm{Fe} 3-\mathrm{xPdxO} 4\end{array}$ & $\begin{array}{l}30 \mathrm{~nm}-1 \mu \mathrm{m} \\
30 \mathrm{~nm}-1 \mu \mathrm{m} \\
\text { Not determined } \\
30-90 \mathrm{~nm} \\
\text { Fot determined }\end{array}$ \\
\hline $\begin{array}{l}\text { Shewannella } \\
(\mathrm{NV}-1, \mathrm{~W} 3-6-1, \mathrm{~W} 3-7-1)\end{array}$ & & $\begin{array}{l}\mathrm{Fe} 3-\mathrm{xMnXO} 4 \\
\text { Fe3-xNdxO4, Fe3-xGdxO4 }\end{array}$ & Not determined \\
\hline
\end{tabular}




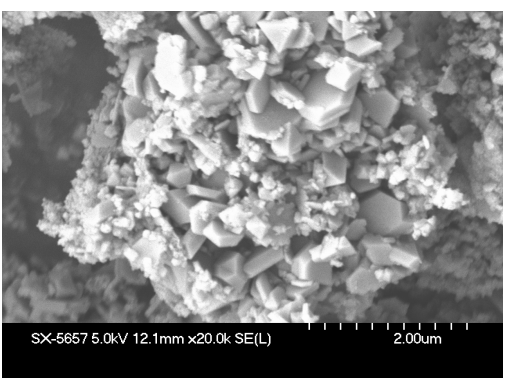

Fig. 5. SEM Co-substituted

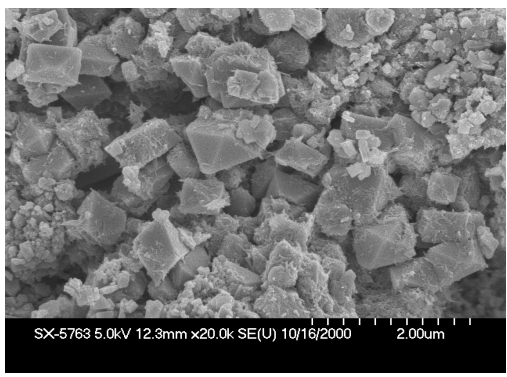

Fig. 8. SEM Cr-substituted

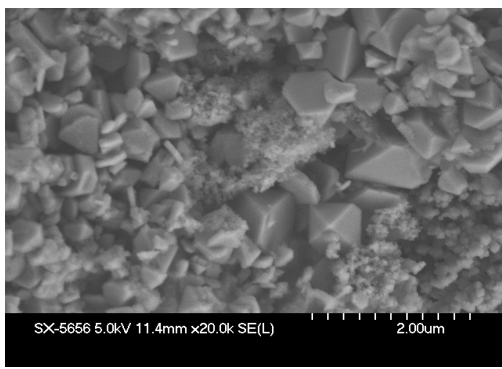

Fig. 11. SEM Ni-substituted

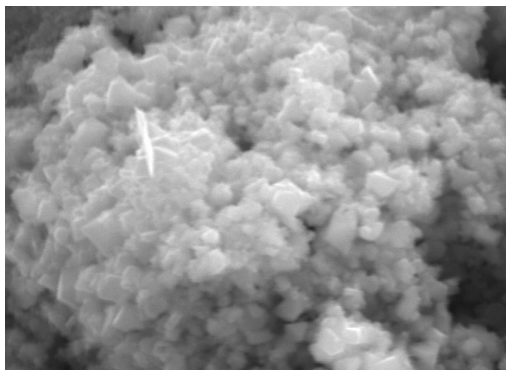

Fig. 14. SEM Mn-substituted

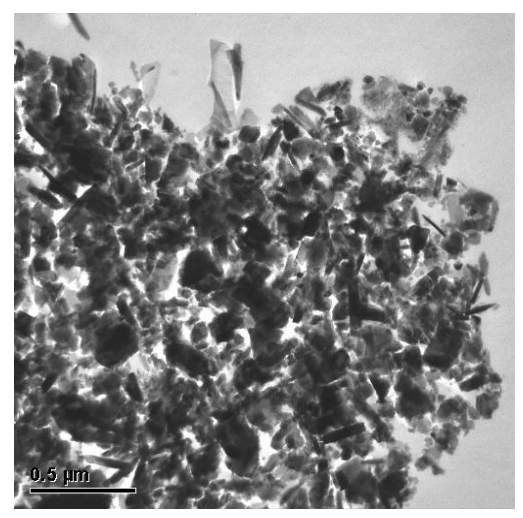

Fig. 6 TEM Co-substituted

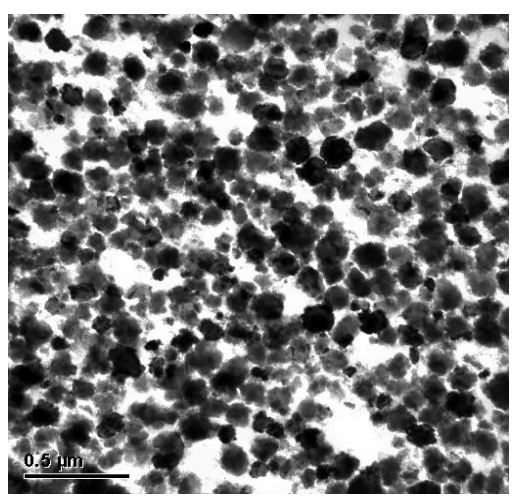

Fig. 9. TEM Cr-substituted

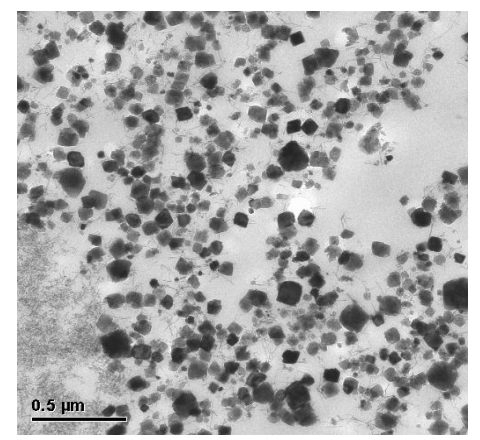

Fig. 12. TEM Ni-substituted

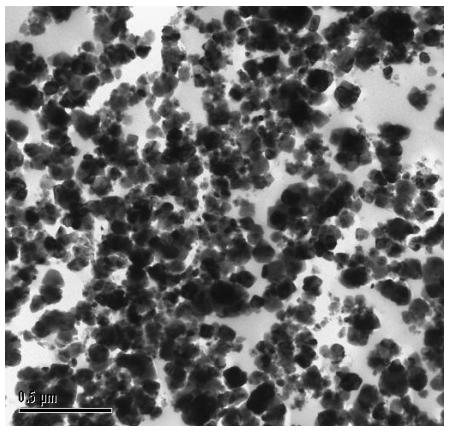

Fig. 15. TEM Mn-substituted

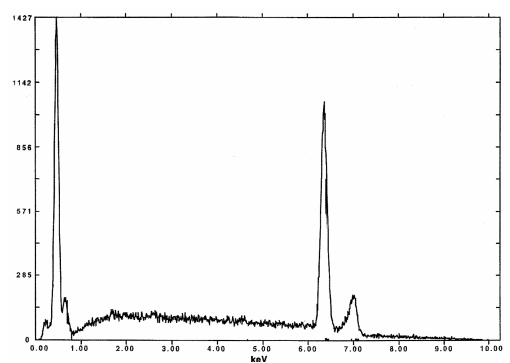

Fig. 7. EXD Co-substituted

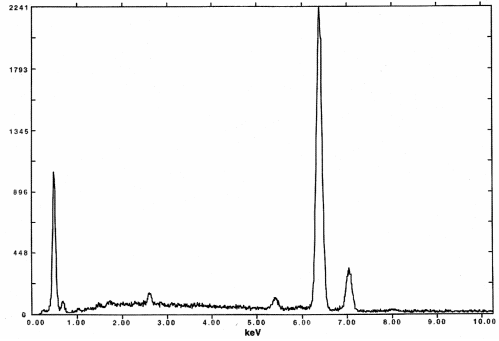

Fig. 10. EXD Cr-substituted

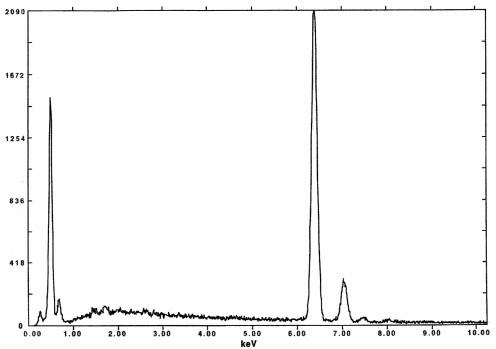

Fig. 13. EXD Ni-substituted

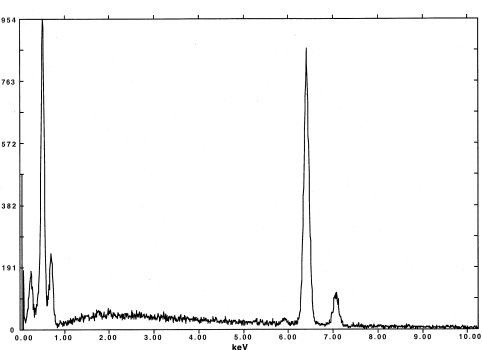

Fig. 16. EXD Mn-substituted 
It is clear that various ferrite compositions can be synthesized as nanoparticles using any of the above approaches. In particular, $\mathrm{Mn}_{\mathrm{x}} \mathrm{Fe}_{1-\mathrm{x}} \mathrm{Fe}_{2} \mathrm{O}_{4}$ ferrites have been reported to have Curie temperatures between 75 and $325^{\circ} \mathrm{C}$ and to have as-synthesized particle sizes between 6 and 20 $\mathrm{nm}{ }^{13,14}$ These physical properties fit well with our requirements for ferrofluid particles. However, there are other compounds, such as Gd-ferrites, that have high pyromagnetic coefficients $(\partial \mathrm{M} / \partial \mathrm{T})_{\mathrm{H}}$, possibly providing a more effective material for field-induced (magnetocaloric) ferrofluid pumping. ${ }^{15}$ For this investigation, we compared three separate ferrofluid compounds: magnetite in oil, $\mathrm{MnZn}$ magnetite in oil and MnZn magnetite in water. Curie temperatures, along with the pyromagnetic coefficient, were measured using a Walker Scientific temperature controlled Hysteresisgraph. Fig. 17 displays a comparison of the intrinsic magnetization of three different compounds: magnetite in oil, MnZn doped magnetite in oil, and MnZn doped magnetite in water. Fig. 18 and 19 display the variation in magnetization, for Magnetite and $\mathrm{MnZn}$ ferrofluids respectively, as the temperature varied from $25^{\circ} \mathrm{C}$ to $85^{\circ} \mathrm{C}$ in $10^{\circ} \mathrm{C}$ increments. It is clear that the $\mathrm{MnZn}$ ferrofluids exhibit a much larger variation in magnetization for the given temperature range. As described previously, this temperature sensitive variation in magnetization generates pressure gradients in the fluid. Subsequently, we should see significant improvements in fluid flow by simply modifying the particles used in the ferrofluid.

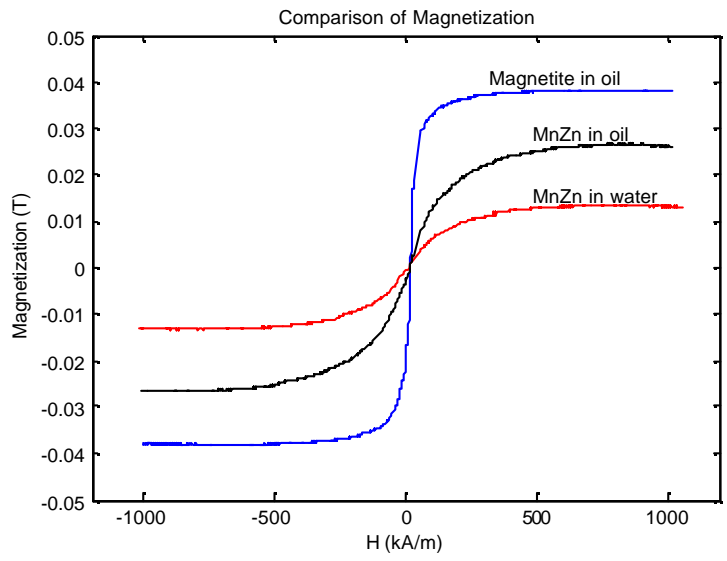

Fig. 17. Comparison of B-H curves at room temperature.

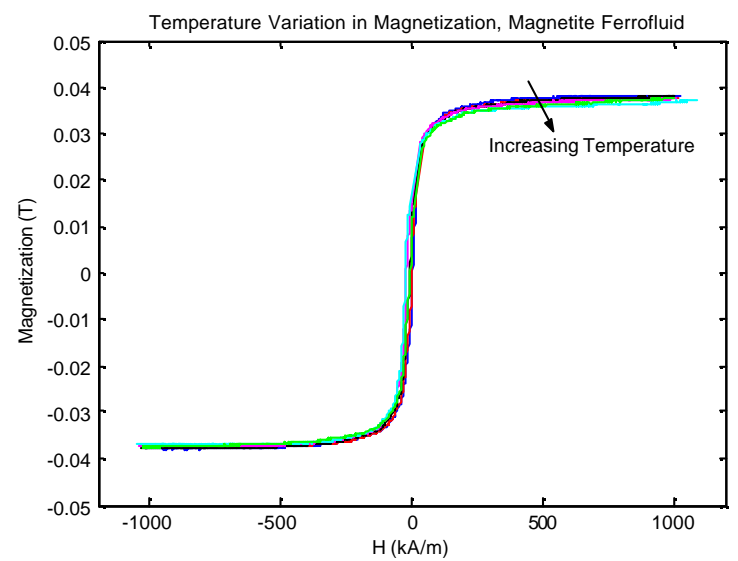

Fig. 18: Magnetite temperature variation.

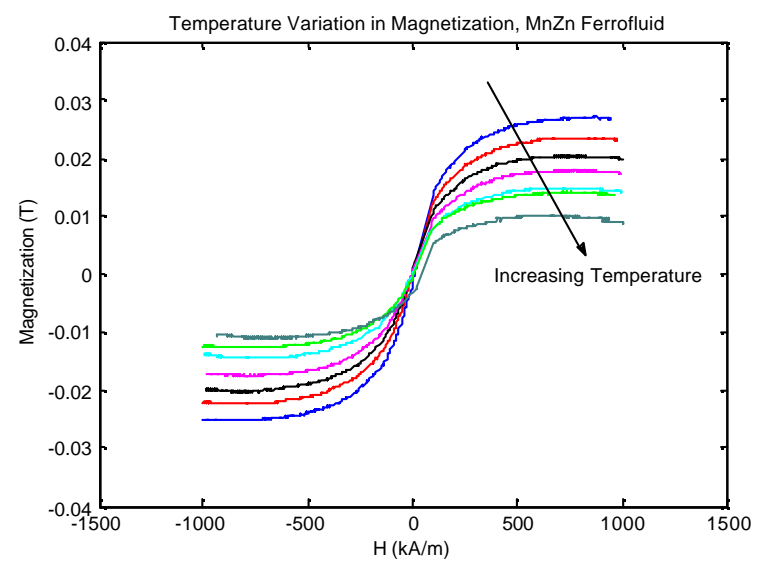

Fig. 19. MnZn temperature variation. 



\section{MODELING OF MAGNETOCALORIC EFFECT}

In order to predict the behavior of a magnetocaloric pump, and aid in the design of systems exploiting this phenomenon, we now summarize the basic thermal, magnetic, and fluid dynamic constitutive relationships of our magnetocaloric pump, displayed in Fig. 1. We assume cylindrical coordinates. In addition, we assume the fluid is incompressible. Our objective is to define the relationship between our heat source, $\dot{\mathrm{q}}$, external magnetic field, $\mathrm{H}$, and the resulting fluid velocity, $\mathrm{v}_{\mathrm{z}}(\mathrm{H}, \mathrm{q})$.

\subsection{CONSERVATION OF ENERGY}

We begin with a simple expression for the energy balance for a differential element of fluid.

$$
\begin{aligned}
& \nabla^{2} \mathrm{~T}+\frac{\dot{\mathrm{q}}}{\mathrm{k}}=\frac{\rho \mathrm{C}_{\mathrm{p}}}{\mathrm{k}} \frac{\partial \mathrm{T}}{\partial \mathrm{t}} \\
& \text { where } \nabla^{2}=\frac{\partial}{\partial \mathrm{r}^{2}}+\frac{1}{\mathrm{r}} \frac{\partial}{\partial \mathrm{r}}+\frac{1}{\mathrm{r}^{2}} \frac{\partial^{2}}{\partial \theta^{2}}+\frac{\partial^{2}}{\partial^{2} \mathrm{z}}
\end{aligned}
$$

While the temperature varies as both a function of radius, $r$, and distance, $\mathrm{z}$, we will simplify our analysis for now by assuming temperature varies only with distance $\mathrm{z}$. Our motivation is to formulate a simple relationship that will provide a straightforward prediction of the fluid flow as a function of external magnetic and thermal fields. However, we will use the full spatial models when we refine our results in the finite element analysis. With these assumptions, we can simplify the above relationship.

$$
\begin{aligned}
\frac{\mathrm{d}^{2} \mathrm{~T}}{\mathrm{dz}^{2}}+\frac{\dot{\mathrm{q}}}{\mathrm{k}} & =\frac{\rho \mathrm{C}_{\mathrm{p}}}{\mathrm{k}} \frac{\partial \mathrm{T}}{\partial \mathrm{t}} \\
& =\frac{\rho \mathrm{C}_{\mathrm{p}}}{\mathrm{k}} \frac{\partial \mathrm{T}}{\partial \mathrm{z}} \mathrm{v}_{\mathrm{z}}
\end{aligned}
$$

We make one final assumption that the temperature gradient is linear. With this assumption, we can establish the following relationship between the temperature gradient, applied heat, and fluid velocity.

$$
\frac{\partial \mathrm{T}}{\partial \mathrm{z}}=\frac{\dot{\mathrm{q}}}{\rho \mathrm{C}_{\mathrm{p}} \mathrm{v}_{\mathrm{z}}}
$$

\subsection{MAGNETIC PRESSURE}

Next, we consider the impact the magnetic field has on the ferrofluid. Our objective is to establish the pressure in the fluid due to variations in the materials properties. We follow the same conservation of energy approach described by Woodson and Melcher. ${ }^{16}$ We begin with the simple expression for the energy stored in a fixed volume of fluid. 


$$
\mathrm{W}_{\mathrm{m}}=\int_{\mathrm{V}}\left(\frac{1}{2} \mathrm{~B} \cdot \mathrm{H}-\mathrm{F} \cdot \zeta\right) \mathrm{dV}
$$

The vectors $\mathrm{B}, \mathrm{H}$, and $\mathrm{F}$ are the magnetic flux density $\left(\mathrm{kg} / \mathrm{s}^{2} \mathrm{~A}\right)$, magnetic field strength $(\mathrm{A} / \mathrm{m})$, and fluid force $\left(\mathrm{N} / \mathrm{m}^{2}\right)$. Equation (6) is the constitutive relationship between the magnetic field intensity through a medium and the resulting magnetic flux density.

$$
\mathrm{B}=\mu_{\mathrm{o}}(\mathrm{M}+\mathrm{H})
$$

We now use variational calculus on Eq. (5) with the intent on developing an expression for the fluid force.

$$
\begin{aligned}
\delta \mathrm{W}_{\mathrm{m}} & =\int_{\mathrm{V}}\left(\frac{1}{2} \mathrm{~B} \cdot \delta \mathrm{H}+\frac{1}{2} \mathrm{H} \cdot \delta \mathrm{B}-\mathrm{F} \cdot \delta \zeta\right) \mathrm{dV} \\
& =\int_{\mathrm{V}}\left(\mu_{0} \mathrm{H} \cdot \delta \mathrm{H}+\frac{1}{2} \mu_{0} \mathrm{H} \cdot \delta \mathrm{M}+\frac{1}{2} \mu_{0} \mathrm{M} \cdot \delta \mathrm{H}-\mathrm{F} \cdot \delta \zeta\right) \mathrm{dV}
\end{aligned}
$$

Since the variational in energy is zero by definition, the term inside the integrand is zero as well. From this, we can establish the force relationship.

$$
\mathrm{F} \cdot \delta \zeta=\mu_{0} \mathrm{H} \cdot \delta \mathrm{H}+\frac{1}{2} \mu_{0} \mathrm{H} \cdot \delta \mathrm{M}+\frac{1}{2} \mu_{0} \mathrm{M} \cdot \delta \mathrm{H}
$$

Our objective is to express each of the first two terms in Eq. (7) as a vector dot project with the variation of the independent displacement, $\delta \zeta$. By doing so, we will be able to define the full expression of the fluid force. We know that the material's magnetization, $\mathrm{M}$, is a function of temperature $(\mathrm{T})$, magnetic field intensity $(\mathrm{H})$, and density $(\rho) .{ }^{17}$ However, Rosenswieg points out that the magnetostrictive effect, the variation with respect to density, is negligible for ferrofluids. Therefore, we restrict our analysis to only the temperature and magnetic field effects. We now use the chain rule to expand the variational of the material's magnetization in terms of each of these variables. In addition, we exploit the fact that the magnetization, $M$, is proportional to the product of the material's susceptibility $(\chi=\partial \mathrm{M} / \partial \mathrm{H})$ and magnetic field intensity.

$$
\begin{aligned}
\mathrm{F} \cdot \delta \zeta & =\mu_{0} \mathrm{H} \cdot \delta \mathrm{H}+\frac{1}{2} \mu_{0} \mathrm{H} \cdot \frac{\partial \mathrm{M}}{\partial \mathrm{H}} \delta \mathrm{H}+\frac{1}{2} \mu_{0} \mathrm{H} \cdot \frac{\partial \mathrm{M}}{\partial \mathrm{T}} \delta \mathrm{T}+\frac{1}{2} \mu_{0} \mathrm{M} \cdot \delta \mathrm{H} \\
& =\mu_{0} \mathrm{H} \cdot \delta \mathrm{H}+\mu_{0} \mathrm{M} \cdot \delta \mathrm{H}+\frac{1}{2} \mu_{0} \mathrm{H} \cdot \frac{\partial \mathrm{M}}{\partial \mathrm{T}} \delta \mathrm{T}
\end{aligned}
$$

We begin by deriving a relationship between the variation of the magnetic field intensity, $\delta \mathrm{H}$, and the variation of the displacement variable, $\delta \zeta$. After a few manipulations, we come to the following expression. 


$$
\begin{aligned}
H \cdot \delta H & =\frac{1}{2} \nabla(H \cdot H) \cdot \delta \zeta \\
& =[H(\nabla \cdot H)+H \times(\nabla \times H)] \cdot \delta \zeta
\end{aligned}
$$

Assuming there is no free current or electrical displacement in the fluid, Ampere's law states that the curl of the magnetic field intensity is zero. Subsequently, we arrive at the following.

$$
\mathrm{H} \cdot \delta \mathrm{H}=\mathrm{H}(\nabla \cdot \mathrm{H}) \delta \zeta
$$

Likewise, since there is only a scalar relationship between the magnetic field intensity and magnetization (the material's susceptibility, $\chi$ ), a similar reduction can be made for the dot product between the magnetization, $\mathrm{M}$, and the variational of the field intensity, $\delta \mathrm{H}$. As stated earlier, we know from Curie-Weiss that magnetization varies with temperature, the $\partial \mathrm{M} / \partial \mathrm{T}$ term in Eq. (9). This is clearly shown in Fig. 19. However, up until now, we have modeled magnetization as a vector. In the formulation in Eq. (9), the change in magnetization as a function of temperature, also referred to as the pyromagnetic coefficient, is a scalar and is a property of the material. In an attempt to avoid confusion, we can represent this same phenomenon as a variation in the material's susceptiblity as a function of temperature.

$$
\mathrm{H} \cdot \delta \mathrm{M}=(\mathrm{H} \cdot \mathrm{H}) \frac{\partial \chi}{\partial \mathrm{T}} \nabla \mathrm{T} \cdot \delta \mathrm{d} \zeta
$$

For completeness, we will also consider the possibility that permeability will vary as a function of the fluid's density as well, the $\partial \mathrm{M} / \partial \rho$ term. In a given volume of fluid, there is a finite number of magnetic nanoparticles. As we compress the fluid, the volume of the fluid decreases, but the number of fluid particles remains the same. Subsequently, we should see an increase in magnetization (or permeability) as the fluid is compressed. We adopt the same methodology as Woodson and Melcher by modeling this effect as a variation in density instead of a variation in volume.

$$
\begin{aligned}
\mathrm{F} \cdot \delta \zeta & =\mu_{0} \mathrm{H} \cdot \delta \mathrm{H}+\mu_{0} \mathrm{M} \cdot \delta \mathrm{H}+\frac{1}{2} \mu_{0} \mathrm{H} \cdot \frac{\partial \mathrm{M}}{\partial \mathrm{T}} \delta \mathrm{T} \\
& =\mathrm{B}(\nabla \cdot \mathrm{H}) \cdot \delta \zeta+\frac{1}{2} \mu_{0}(\mathrm{H} \cdot \mathrm{H}) \frac{\partial \chi}{\partial \mathrm{T}} \nabla \mathrm{T} \cdot \delta ?
\end{aligned}
$$

Finally, exploiting a few identities and the divergence theorem, we can manipulate the third term in Eq. (13) to finally define an expression that permits us to separate all of the force terms from the virtual displacement. We can now fully define the force experienced by the fluid.

$$
\mathrm{F}=\mathrm{B}(\nabla \cdot \mathrm{H})+\frac{1}{2} \mu_{\mathrm{o}}\left(\mathrm{H} \cdot \frac{\partial \mathrm{M}}{\partial \mathrm{T}}\right) \nabla \mathrm{T}
$$

It is clear that there is the potential for three sources of forces on the fluid. The first term in (14) represents the field magnetic pressure on the fluid. As an example, when a column of fluid is exposed to a magnetic field, this magnetic pressure forces the fluid into an equilibrium configuration with the magnetic field. The second term, which is our primary interest, is the magnetocaloric force. Clearly the fluid experiences a change in force associated with a change in temperature. The final component 
represents the magnetostrictive component on the fluid. In a typical hydrocarbon or water-based ferrofluid, the compressibility of the carrier fluid is about 100 times greater than the particles, so the magnetostriction of the particle is negligible in terms of the compression of the fluid. Inside the solenoid in Fig. 1, the field is uniform so the first term is neglected. Therefore, for our single degreeof-freedom problem, the force reduces to the following where $H$ and $M$ represents the scalar magnitude of the magnetic field intensity and magnetization, respectively.

$$
\begin{aligned}
\mathrm{F} & =\frac{\partial \mathrm{P}}{\partial \mathrm{z}} \\
& =\frac{1}{2} H^{2} \frac{\partial \chi}{\partial \mathrm{T}} \frac{\partial \mathrm{T}}{\partial \mathrm{z}} \\
& =\frac{1}{2} H \frac{\partial M}{\partial \mathrm{T}} \frac{\partial \mathrm{T}}{\partial \mathrm{z}}
\end{aligned}
$$

Now, it should be clear that, to achieve the greatest pressure gradient, it is desirable to maximize the $\partial \mathrm{M} / \partial \mathrm{T}$ term. Inspection of Fig. 2 shows that this is possible through designing fluids with Curie temperatures as close as possible to the maximum operating temperature. In addition, it is desirable to maximize the saturation magnetization.

\subsection{FLUID DYNAMICS}

The final component in our examination of the constitutive relationships is the fluid dynamics. We assume that the fluid flow is incompressible. We use Navier-Stokes to express the relationships between external forces on the fluid and the fluid flow.

$$
\begin{aligned}
& \rho \frac{\mathrm{Dv}}{\mathrm{Dt}}=\mathrm{F}_{\mathrm{z}}-\frac{\partial \mathrm{P}}{\partial \mathrm{z}}+v \nabla^{2} \mathrm{v}_{\mathrm{z}} \\
& \text { with } \frac{\mathrm{D}}{\mathrm{Dt}}=\frac{\partial}{\partial \mathrm{t}}+\mathrm{v}_{\mathrm{r}} \frac{\partial}{\partial \mathrm{r}}+\frac{\mathrm{v}_{\theta}}{\mathrm{r}} \frac{\partial}{\partial \theta}+\mathrm{v}_{\mathrm{z}} \frac{\partial}{\partial \mathrm{z}} \\
& \text { and } \nabla^{2}=\frac{\partial}{\partial \mathrm{r}^{2}}+\frac{1}{\mathrm{r}} \frac{\partial}{\partial \mathrm{r}}+\frac{1}{\mathrm{r}^{2}} \frac{\partial^{2}}{\partial \theta^{2}}+\frac{\partial^{2}}{\partial^{2} \mathrm{z}}
\end{aligned}
$$

For the cylindrical element of fluid, we assume a steady state condition as well as no velocity in the $\theta$ - and $\mathrm{r}$-direction (e.g., the fluid is moving uniformly in the $\mathrm{z}$ direction). With these assumptions, Navier-Stokes collapses to the expression in Eq. (17).

$$
\frac{\partial \mathrm{P}}{\partial \mathrm{z}}=\mathrm{v} \frac{1}{\mathrm{r}} \frac{\partial}{\partial \mathrm{r}}\left(\mathrm{r} \frac{\partial \mathrm{v}_{\mathrm{z}}}{\partial \mathrm{z}}\right)
$$

If we assume a no-slip condition at the boundary surface $(r=R)$ and finite fluid velocity at the center of the channel $(r=0)$, the velocity profile is the standard form found in most fluid dynamics references.

$$
\mathrm{v}_{\mathrm{z}}(\mathrm{r})=-\frac{\mathrm{R}^{2}}{4 \mathrm{v}} \frac{\partial \mathrm{P}}{\partial \mathrm{z}}\left(1-\left(\frac{\mathrm{r}}{\mathrm{R}}\right)^{2}\right)
$$


Given the velocity profile, we can extract the flow rate.

$$
\begin{aligned}
Q & =\int_{0}^{\mathrm{R}} \mathrm{v}_{\mathrm{z}}(\mathrm{r}) 2 \pi \mathrm{rdr} \\
& =-\frac{\mathrm{p} \mathrm{R} \mathrm{R}^{2}}{8 \mathrm{v}} \frac{\partial \mathrm{P}}{\partial \mathrm{z}}
\end{aligned}
$$

The average velocity, $\mathrm{v}_{\mathrm{z}}$, of the fluid is now expressed as the ratio of the fluid flow rate, $\mathrm{Q}$, over the channel cross sectional area.

$$
\mathrm{v}_{\mathrm{z}}=-\frac{\mathrm{R}^{2}}{8 \mathrm{v}} \frac{\partial \mathrm{P}}{\partial \mathrm{z}}
$$

\subsection{COUPLING RELATIONSHIPS}

The previous analysis provides three fundamental relationships in Eqs. (4), (13), and (20). Our objective is to establish a fundamental estimate of the fluid velocity, $\mathrm{v}_{\mathrm{z}}$, as a function of the external magnetic field, $\mathrm{H}$, and heat, $\dot{\mathrm{q}}$. Simple algebraic manipulation results in the following relationship.

$$
\mathrm{v}_{\mathrm{z}}=\sqrt{\frac{\mathrm{R}^{2}}{16 v} \frac{\partial \mu}{\partial \mathrm{T}} \mathrm{H}^{2} \frac{\dot{\mathrm{q}}}{\rho \mathrm{C}_{\mathrm{p}}}}
$$





\section{EXPERIMENTAL INVESTIGATION}

We now provide a simple comparison of magnetocaloric energy conversion, comparing an oil and water based ferrofluid using the same series of particles, $\mathrm{Mn}_{0.5} \mathrm{Zn}_{0.5} \mathrm{Fe}_{2} \mathrm{O}_{4}$, which has a Curie temperature of approximately $150^{\circ} \mathrm{C}$. From the previous analysis, it is advantageous to design a ferrofluid with a low viscosity, high specific heat, large pyromagnetic coefficient and Curie temperature close to the maximum cycle temperature. The wide array of potential applications may require either an oil-based or water-based carrier fluid. For example, all electromagnetic actuators have coincident magnetic and thermal fields. The maximum operating torque of electric actuators is limited due to thermal constraints on the coils. Subsequently, it is possible to cool an electric motor using ferrofluids. The advantage to such an approach is two-folds. First, there is no need for an external pump, the internal magnetic and thermal fields provide the energy for fluid propulsion. Second, the system is self regulating. As the motor temperature increases, the fluid flow increases. Such applications require the use of oil based ferrofluids for electrical insulation.

Fig. 20 and Fig. 21 show the basic configuration for this series of experiments. We have a simple $2 \mathrm{~mm}$ diameter glass tube with a $40 \mathrm{~mm}$ long column of ferrofluid. The heat source is a coil of nichrome wire. The coil wraps around the glass tube and is approximately $15 \mathrm{~mm}$ long and has a 4.4 $\Omega$ resistance. The objective of this experiment is to establish the impact the ferrofluid has on the measured flow rate. We compared three different series of ferrofluids: magnetite in oil, $\mathrm{Mn}_{0.5} \mathrm{Zn}_{0.5} \mathrm{Fe}_{2} \mathrm{O}_{4}$ in oil and $\mathrm{Mn}_{0.5} \mathrm{Zn}_{0.5} \mathrm{Fe}_{2} \mathrm{O}_{4}$ in water. The experiments are controlled so that the only variable that changes is the ferrofluid. We have thermocouples measuring the fluid temperature at the heat source and at the end of the fluid column. We use the same heating element with the same excitation $(2.6 \mathrm{~V}, 0.56 \mathrm{~A})$ for each experiment. The average field strength across the column of fluid was $2.7 \mathrm{e} 5 \mathrm{~A} / \mathrm{m}$. We use a digital video camera to record the experiment. We estimate the fluid velocity, via the digital video output, by measuring the displacement, observed with the ruler in Fig. 21 , and time, recorded on the time stamp on the video. The results of these experiments are tabulated in Table 4. The last three columns represent the estimated flow, flow estimate from the finite element analysis, and the measured flow. The first observation is that we achieve approximately an order of magnitude increase in flow, at lower temperatures, than was previously possible with conventional magnetite-based ferrofluids. However, we also observe that, in each case, the actual flow was three to six times below the estimated flow. There could be some error in the measured velocity. We are not accounting for acceleration, displacement accuracy is on the order of $0.2 \mathrm{~mm}$, resolution of the time stamp is $10 \mathrm{~ms}$. For the estimate, we are assuming the field is constant across the diameter of the tube. While we know the amount of power generated by the heating element, there is some uncertainty in how much of this heat is transferred to the fluid. To overcome this problem, we use thermocouples at the inlet and outlet to measure the temperature gradient. We then use Eq. (13) to estimate the pressure gradient that is substituted into Eq. (20) for our estimated velocity.

Next, we explore the possibility of improving our velocity estimates with finite element analysis. We use the same constitutive relationships described above for the magnetic, thermal and fluid dynamic models, but now we resolve to use finite element analysis to refine the spatial variations in the constitutive relationships. This problem is complicated somewhat in that there is significant coupling between each of the three domains (thermal, magnetic, and fluid dynamics). We have already discussed how the magnetic and thermal fields produce pressure gradients in the fluid. However, fluid flow in the channel impacts the thermal distribution. In addition, the fluid has a temperature dependent magnetic susceptibility that impacts the magnetic field. To include each of these phenomena, we use the multiphysics finite element package, Femlab. Fig. 22 through Fig. 25 display the results of the analysis for our water based $\mathrm{Mn}_{0.5} \mathrm{Zn}_{0.5} \mathrm{Fe}_{2} \mathrm{O}_{4}$ ferrofluid under the same conditions as described 
previously. The results are tabulated in Table 4 as well. Clearly, the resulting predicted velocities are considerably closer than the simplified analysis. The finite element analysis (FEA) predicts velocities anywhere from 5\% to 53\% over the actual flow. It is possible to refine the models more to include variations in viscosity due to magnetic and thermal variations.

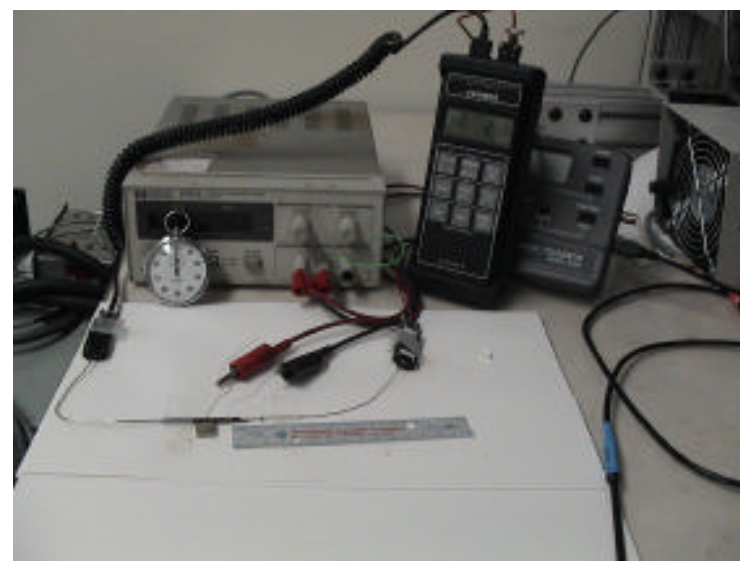

Fig. 20. Experimental setup.

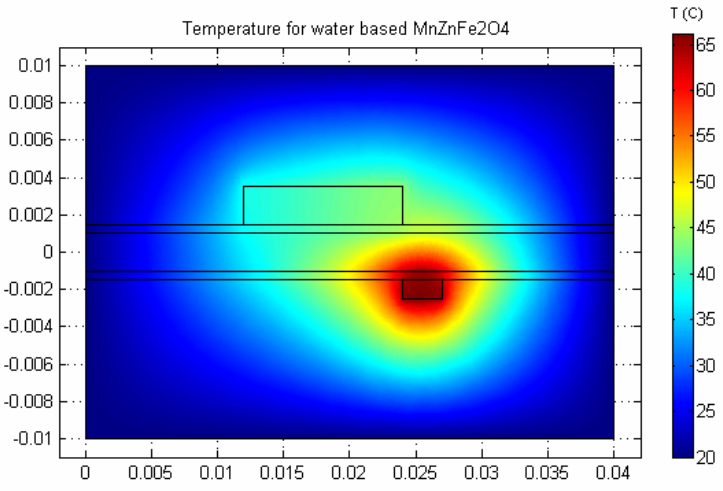

Fig. 22. Temperature distribution.

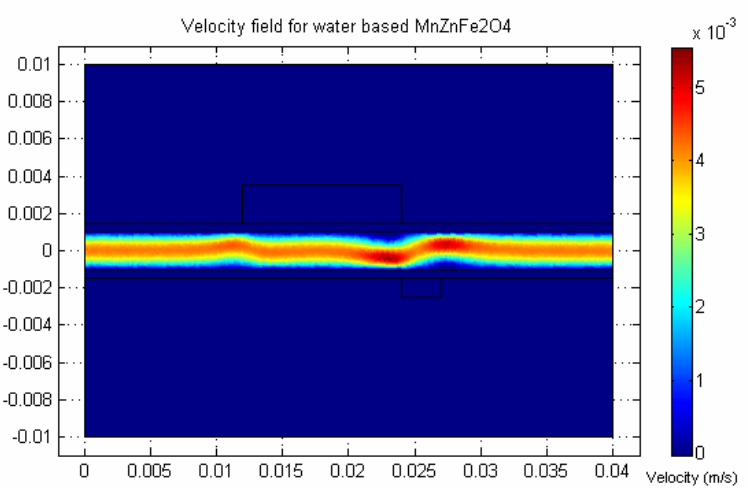

Fig. 24. Velocity field.

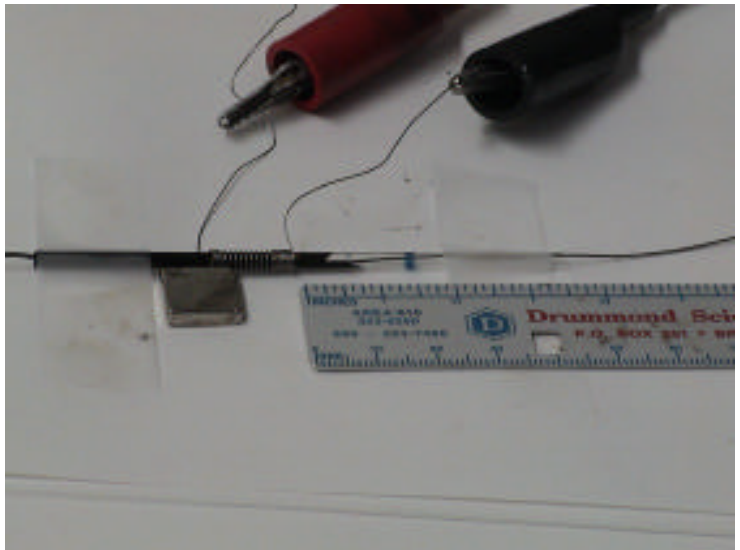

Fig. 21. Closeup of fluid.

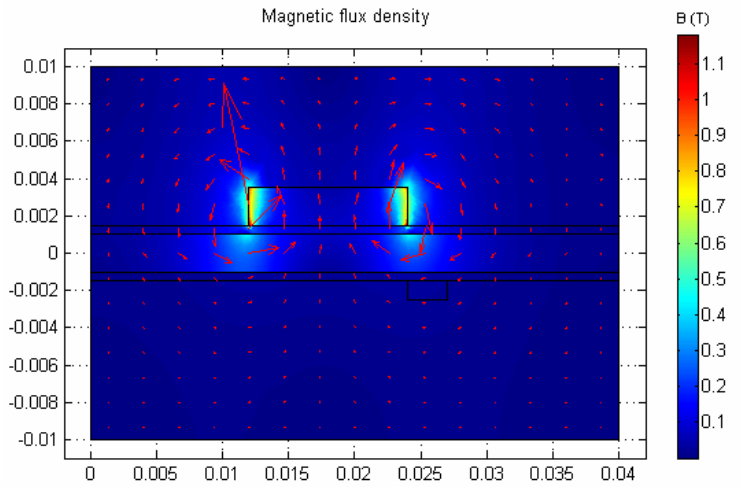

Fig. 23: Magnetic field.

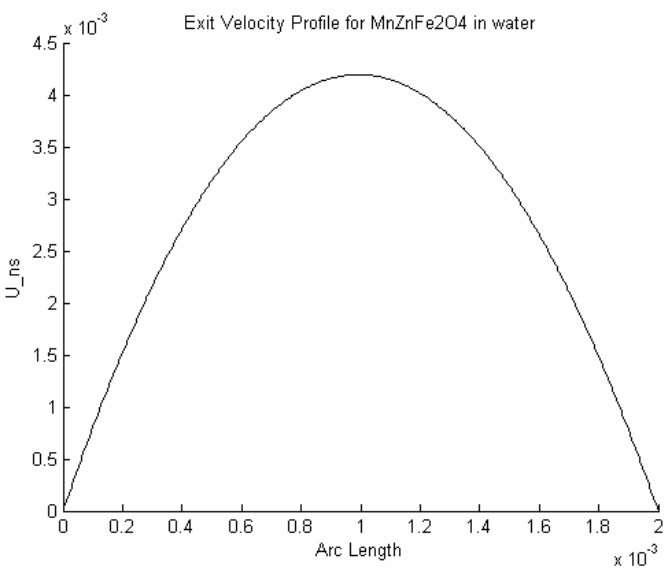

Fig. 25. Velocity profile. 
Table 4: Magnetocaloric pump comparison.

\begin{tabular}{|l|c|c|c|c|c|c|c|c|}
\hline Material & $\begin{array}{c}\text { Specific } \\
\text { Grav. }\end{array}$ & $\begin{array}{c}\text { Viscosity } \\
(\mathrm{mPa}-\mathrm{s})\end{array}$ & $\begin{array}{c}\mathrm{Ms} \\
(\mathrm{mT})\end{array}$ & $\begin{array}{c}\mathrm{T}_{\text {low }} \\
\left({ }^{\circ} \mathrm{C}\right)\end{array}$ & $\begin{array}{c}\mathrm{T}_{\text {hi }} \\
\left({ }^{\circ} \mathrm{C}\right)\end{array}$ & $\begin{array}{c}\mathrm{v}_{\mathrm{x}}(\mathrm{est}) \\
(\mathrm{mm} / \mathrm{s})\end{array}$ & $\begin{array}{c}\mathrm{v}_{\mathrm{x}}(\mathrm{FEA}) \\
(\mathrm{mm} / \mathrm{s})\end{array}$ & $\begin{array}{c}\mathrm{v}_{\mathrm{x}} \\
(\mathrm{mm} / \mathrm{s})\end{array}$ \\
\hline $\mathrm{Fe}_{3} \mathrm{O}_{4}$ in oil & 1.40 & 375 & 35 & 74 & 86 & 0.42 & 0.23 & 0.17 \\
\hline $\mathrm{Mn}_{0.5} \mathrm{Zn}_{0.5} \mathrm{Fe}_{2} \mathrm{O}_{4}$ in oil & 1.52 & 380 & 25 & 48 & 61 & 3.25 & 1.60 & 1.59 \\
\hline $\mathrm{Mn}_{0.5} \mathrm{Zn}_{0.5} \mathrm{Fe}_{2} \mathrm{O}_{4}$ in water & 1.37 & 83 & 11 & 46 & 59 & 4.67 & 1.57 & 2.10 \\
\hline
\end{tabular}





\section{LAB-ON-A-CHIP APPLICATION}

For now, our motivation is to develop models that provide reasonable estimates of fluid flow and can aid in the design of systems that exploit the magnetocaloric effect. As an example, we consider the design of a microfluidic pump for "lab-on-a-chip" (LOC) applications. A popular method for controlling the flow of fluids in LOC systems is based on deforming diaphragms driven by piezoelectric, ${ }^{18,19}$ thermopneumatic, ${ }^{20,21}$ electrostatic ${ }^{22,23}$, electromagnetic ${ }^{24}$, and shape memory actuation $^{25,26}$. The advantage of this approach to micropump design is the independence of the fluid medium. However, the deformable diaphragm approach does require deflecting a material at a high frequency. This has two drawbacks. First, the fluid flow is pulsating, not continuous. Second, the fatigue life can be relatively short. For example, the Shape Memory Alloy (SMA) pump described by $\mathrm{Xu}$ has a fatigue life of approximately $4 \times 10^{7}$ cycles. ${ }^{26}$ The operating frequency is $100 \mathrm{~Hz}$, leading to approximately 111 hours of operation before probable failure. This limitation has led to more recent work that focuses on field-induced pumps that require no moving mechanical parts. Culbertson describes an electroosmotic (ion drag) pump based on high differential voltage between inlet and outlet channels. ${ }^{27}$ However, while the electroosmotic approach is attractive based upon a lack of moving mechanical parts, this approach requires high voltage levels $(\sim 1000 \mathrm{~V})$, complicating miniaturization of the power electronics. Field induced flow based on ferrofluids may provide an elegant approach to LOC microfluidic pumping. First, many DNA amplification and chemical processes require thermal cycling (heating and cooling) of the fluid that could also serve as the source of the thermal gradient for the field induced pumping. Second, magnetic sensing and detection systems, such as the Bead Array Counter developed by the Naval Research Laboratory, rely on magnetic sensors and microbeads to detect the presence and concentration of bioagent DNA. ${ }^{28}$ It may be possible to use the same particles for both the magnetic sensing and field induced pumping. Third, this methodology requires no moving mechanical parts (increasing reliability) and requires only the addition of an external magnetic field (no need for a high voltage source).

Fig. 26 shows a LOC with a 50 micron (approximately the width of a single hair) by 10 micron channel loaded with a $15 \mathrm{~mm}$ column of oil based $\mathrm{Mn}-\mathrm{Zn}$ ferrofluid. The average flow rate, when the thermoelectric heater is energized, is 2 microns/sec. The predicted velocity from the pipe model is 48 microns/sec. However, as before, the finite element model provides a closer match (1.4 microns/sec) to the actual fluid velocity. 


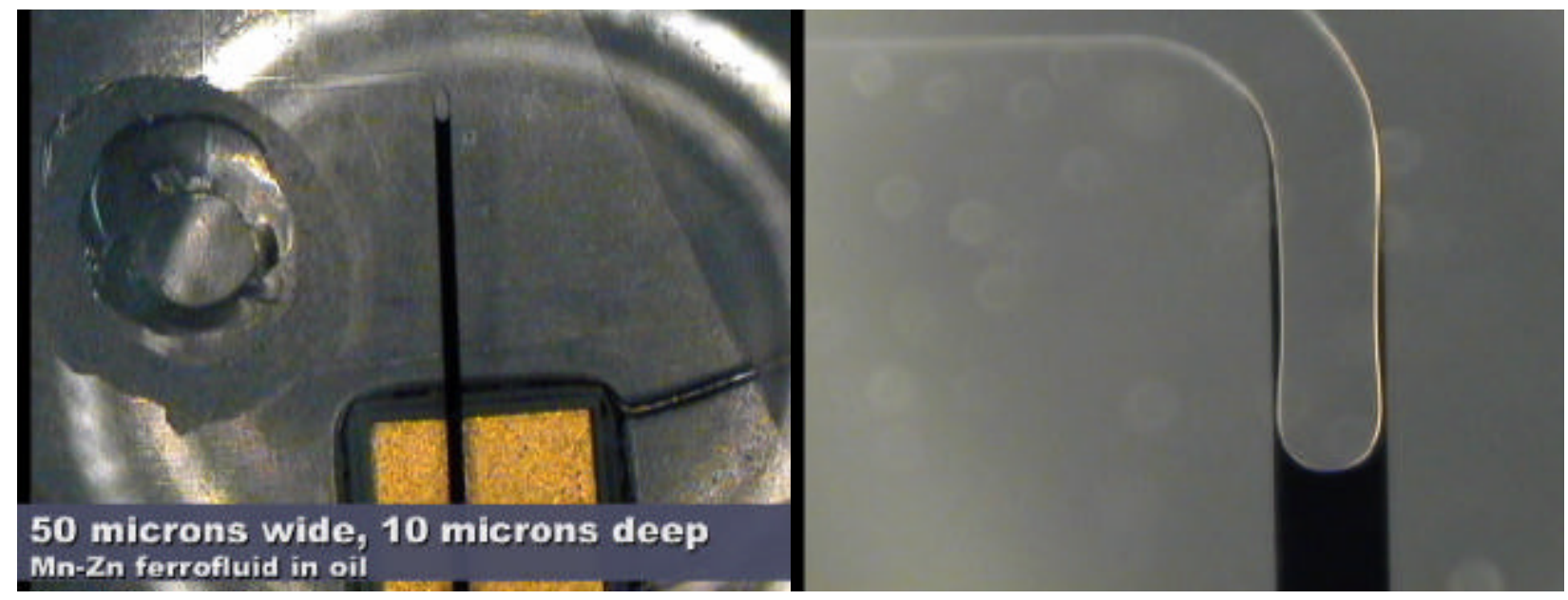

Fig. 26. LOC with ferrofluid and heating element.

Fig. 27. Closeup of LOC with ferrofluid.
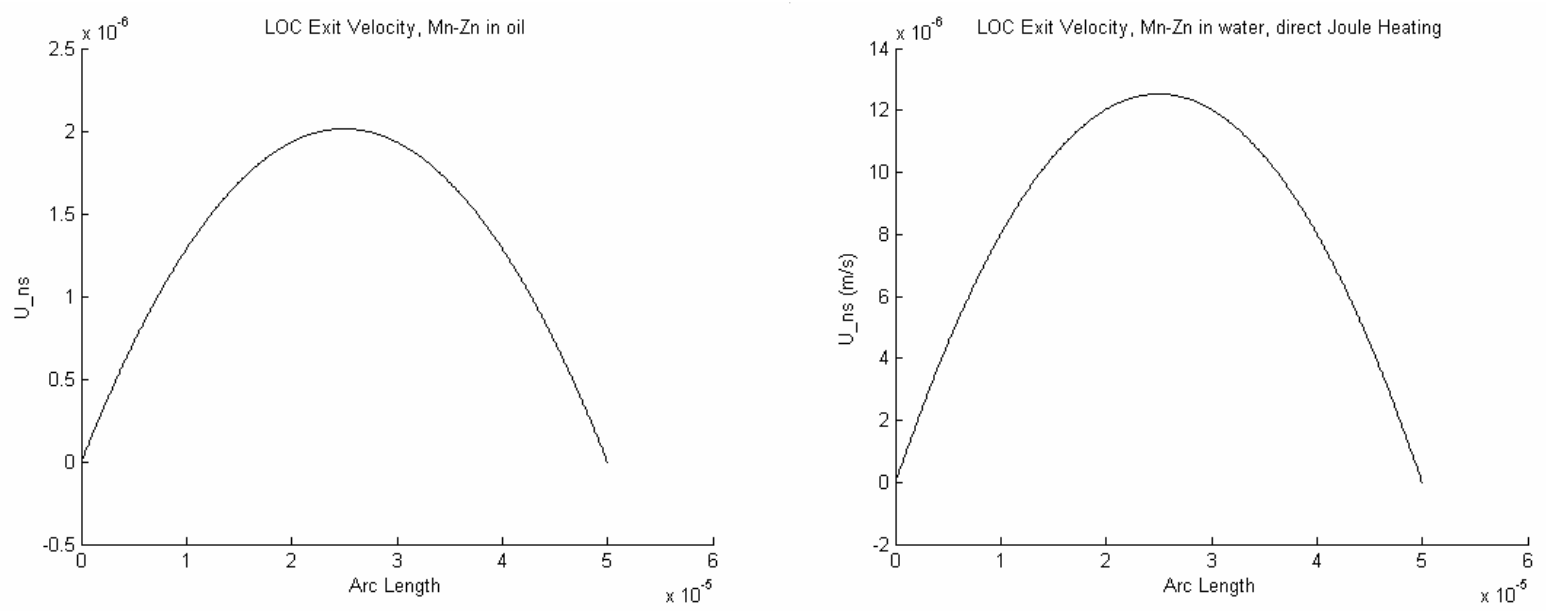

Fig. 28. Oil based Mn-Zn ferrofluid in LOC.

Fig. 29. Water based Mn-Zn ferrofluid in LOC.

In the design process, we considered two methods for supplying the heat: an external thermoelectric heater (Figure 30) and an integrated joule heating element (Figure 31). The external thermoelectric heater provided the ability to modify existing chips with a commercial heating element. However, our finite element analysis and experimentation showed that this approach lacks in efficiency. The heat must first pass through the glass before heating the fluid. This approach to heating lacks the ability to focus the heat directly on the fluid. In contrast, the finite element analysis shows that, by locating the integrated joule heating element in direct contact with the fluid channel, we can better control the heat distribution on the column of fluid. Fig. 29 suggests that we should expect approximately an order of magnitude increase in flow rate if we use water based Mn-Zn ferrofluids and move the heating element directly adjacent to the column of fluid. As an example, we used photolithographic techniques and a metal liftoff process to pattern gold heating coils directly onto the glass substrate adjacent to the fluid channels. There are three advantages to this approach. First, the heat is directly focused on the fluid, reducing the amount of power required for heating. Our required power for heating drops from $1.5 \mathrm{~W}$ to $35 \mathrm{~mW}$. This reduction in power requirements leads to the second advantage to this approach. The two elements shown in Figure 31 have an electrical 
impedance of $250 \Omega$. A simple $3 \mathrm{~V}$ battery, similar to those used for hand held calculators, provides enough current to heat the fluid to our target levels. Note, to avoid generation of gaseous species from electrolysis of the water-based ferrofluid, a passivation layer (100 nm of silicon dioxide) was deposited upon the gold metallization using plasma-enhanced chemical vapor deposition.

The final advantage is that the heating is localized. All of the previous analysis shows considerable agreement between the finite element model of the magnetocaloric energy pump and the experimental results. We now exploit this model to assist in the design process. It is possible to have multiple stages of coincident magnetic and thermal zones. The finite element analysis aides in quantifying the spacing between these zones. This spacing provides an effective fluid column length for each stage. Since the flow is laminar, flow rate is inversely proportional to the column length. By having multiple stages, it is possible to effectively reduce the fluid column length for each stage, significantly increasing the fluid flow rate. Our objective was to demonstrate a mobile platform for conducing lab-on-a-chip operations. The final system, displayed in Fig. 32 and Fig. 33, can operate off of a $3 \mathrm{~V}$ or $9 \mathrm{~V}$ battery. The integrated joule heating element is etched in glass while the microfluidic channel is etched in the adjoining surface. We compared three materials for the channel. The first, glass, works well with oil and water based ferrofluids, but was not flexible and difficult to clean. The second material, SU-8, worked well with water and oil, permanently attaches to the glass, but was likewise difficult to clean. The final material, PDMS, worked well with water based ferrofluids, was easy to clean and reuse, but proved difficult to work with oil based fluids.

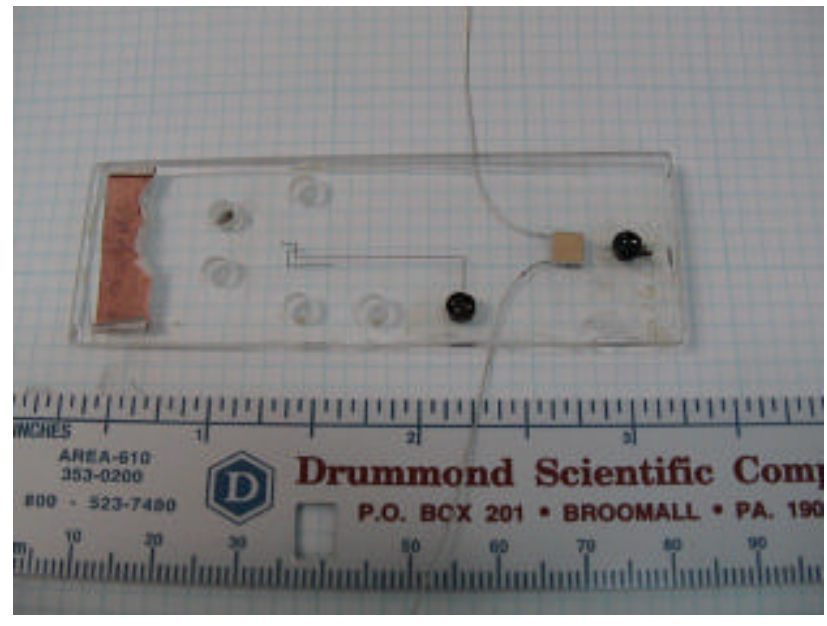

Figure 30: LOC with external THE.

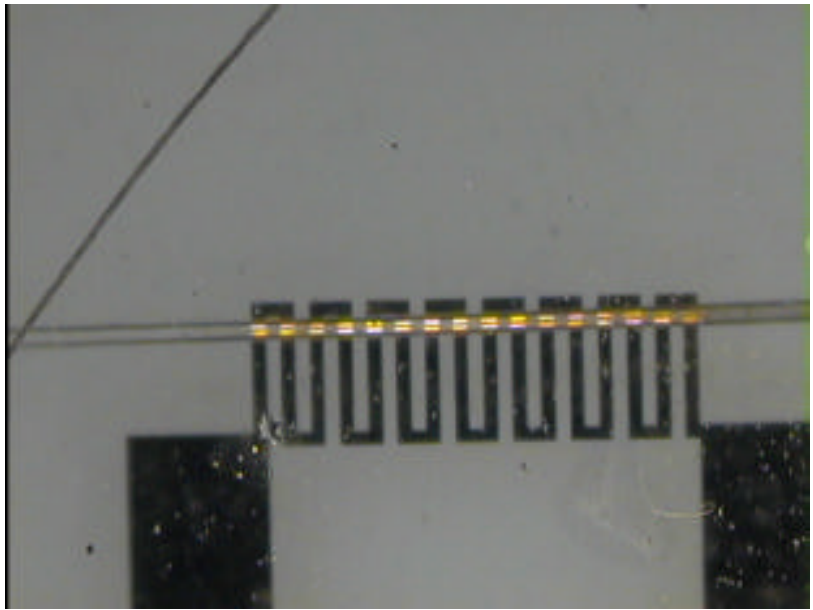

Figure 31: LOC with integrated joule heating. 


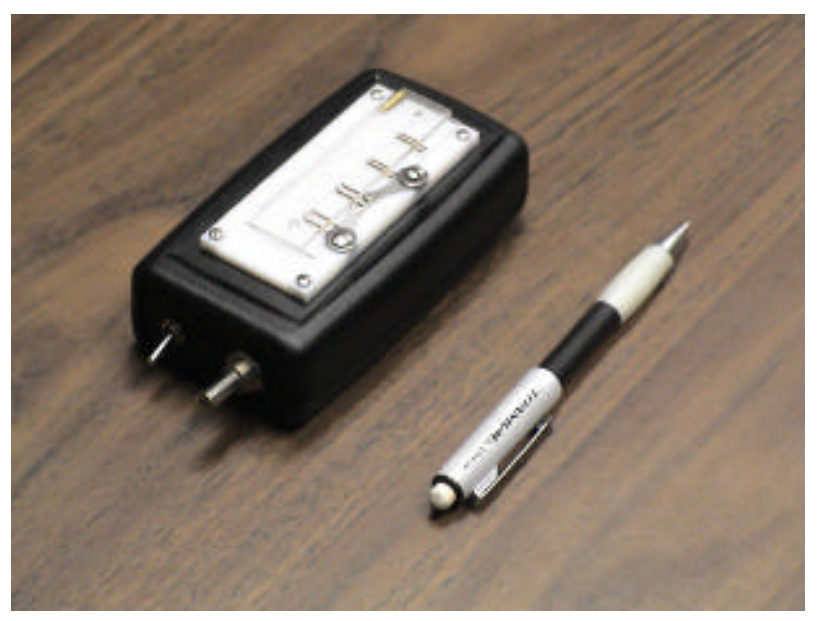

Fig. 32. Portable unit.

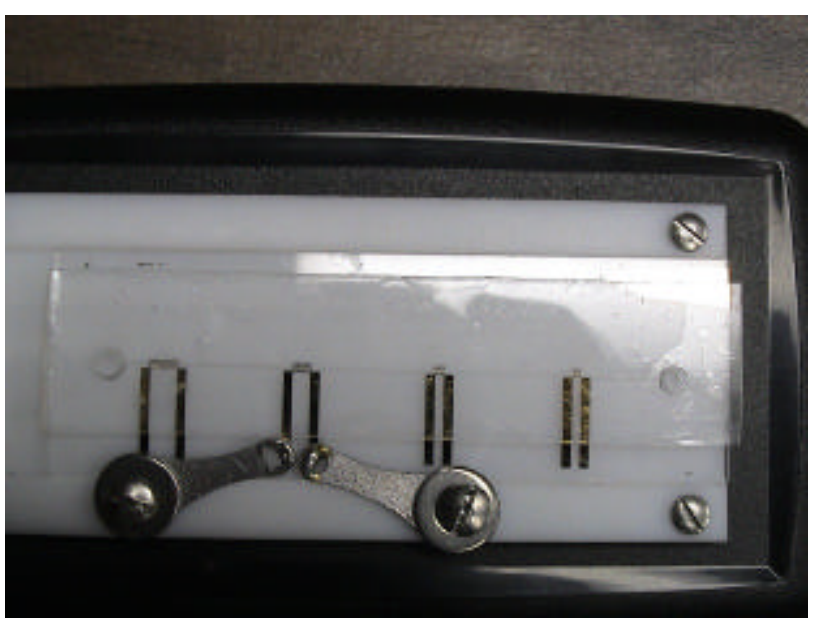

Fig. 33. Chip in portable unit. 


\section{CONCLUSION}

There has been a great deal of effort devoted towards developing smart materials for advanced actuation systems. In this manuscript, we describe a material, ferrofluid, that exhibits a field induced flow when exposed to coincident magnetic and thermal fields. We have characterized the constitutive thermodynamic equations and shown how particle characteristics aid in controlling the performance of such fluids under varying conditions. The primary goals of this paper are to expose the readers to a material, provide insight into its behavior, describe synthesis procedures, and finally describe a few applications that exploit the novel behavior of the fluid. The approach demonstrated the potential for using the fluid in future "lab-on-a-chip" technology. The primary motivation with this application is to demonstrate a "dual-use" of the particles, serving both in terms of sensing and fluid control. Future research is focusing on further chip design and optimization, particle design for increased

pyromagnetic coefficients, and comparing the chemical and biological synthesis procedure to quantify the quality of particle synthesis. 



\section{REFERENCES}

1. Nethe, A., T. Schoppe and H. Stahlmann, "Ferrofluid Driven Actuator for a Left Ventricular Assist Device," Journal of Magnetism and Magnetic Materials, 201, 423-426 (1999).

2. Martin, B. "A Magnetic Colloid System for Isolation of Rare Cells from Blood for FISH Analysis," Prenatal Diagnosis, 17 (11) 1059-1066 (1997).

3. Raj, K., B. Moskowitz and R. Casciari, "Advances in Ferrofluid Technology," Journal of Magnetism and Magnetic Materials, 149, 174-180 (1995).

4. Cao, L and H. Schwartz, "Oscillation, Instability, and Control of Stepper Motors," Nonlinear Dynamics, 18 (4), 383-404 (1999).

5. http://www.ferrofluidics.com

6. Resler, E. and R. Rosensweig, "Regenerative Thermomagnetic Power," Journal of Engineering for Power, 399-406 (1967).

7. $\quad$ Rosensweig, R., Ferrohydrodynamics, Dover Publications, Inc., Mineola, NY, 1985.

8. Liu, S., J. Zhou, C. Zhang, C. Cole, M. Josifovska and T. Phelps, T., "Thermophilic Fe(III)Reducing Bacteria from the Deep Subsurface: The Evolutionary Implications," Science, 277, 11061109 (1997).

9. Roh, Y., R. Lauf, A. McMillan, C. Zhang, C. Rawn, J. Bai, and T. Phelps, "Microbial Synthesis and the Characterization of Metal-Substituted Magnetites,", Solid State Communications, 118, 529-534 (2001).

10. Roh, Y., R. J. Lauf, A.D. McMillan, C. Zhang, C. J. Rawn, J. Bai, T. J. Phelps. Microbial synthesis and the characterization of some metal-doped magnetite, Solid State Communications, 118 (10), 529-534.

11. International Data for Diffraction Data. 1999. JCPDS-International Center for Diffraction Data. (http://www.icdd.com)

12. Zhang, C., H. Vali, C. Romanek, T. Phelps and S. Liu, "Formation of Single-Domain Magnetite by a Thermophilic Bacterium," American Mineralogist, 83, 1409-1418 (1998).

13. Upadhyay, R., K. Davies, S. Wells, and S. Charles, "Preparation and characterization of ultra-fine $\mathrm{MnFe}_{2} \mathrm{O}_{4}$ and $\mathrm{Mn}_{x} \mathrm{Fe}_{1-x} \mathrm{Fe}_{2} \mathrm{O}_{4}$ spinel systems: I. particles," J. Magn and Mag Mater, 132, 249-57 (1994).

14. Upadhyay, R., R. Mehta, K. Parekh, D. Srinivas and R. Pant, "Gd-substituted ferrite ferrofluid: a possible candidate to enhance pyromagnetic coefficient," Journal of Magnetism and Magnetic Materials, 201, 129-132 (1999).

15. Woodson, H. and J. Melcher, Electromechanical Dynamics, Part II: Fields, Forces, and Motion, Robert Krieger Publishing, 1968, pp. 456-462.

16. Bashtovoy, V., B. Berkovsky and A. Vislovich, Introduction to Thermomechanics of Magnetic Fluids, Hemisphere Publishing Col., 1988.

17. Park, J., K. Yoshida and S. Yokota, "Resonantly Driven Piezoelectric Micropump: Fabrication on a Micropump Having High Power Density," Mechatronics, 9, 687-702 (1999).

18. Olsson,A., O. Larsson, J. Holm, L. Lundbladh, O. Ohman and G. Stemme, "Valve-less Diffuser Micropumps Fabricated Using Thermoplastic Replication," Sensors and Actuators A, 64, 6368 (1998).

19. Wego, A. and L. Pagel, “A Self-Filling Micropump Based on PCB Technology,” Sensors and Actuators A, 88, 220-226 (2001).

20. Jeong, O. and S. Yang, "Fabrication and Test of a Thermopneumatic Micropump with a Corrugated P+ Diaphragm," Sensors and Actuators A, 83,249-255 (2000). 
21. Voigt, P., G. Schrag and G. Wachutka, "Electrofluidic Full-System Modelling of a Flap Valve Micropump Based on Kirchhoffian Network Theory," Sensors and Actuators A, 66, 9-14 (1998).

22. Francais, O. and I. Dufour, "Dynamic Simulation of an Electrostatic Micropump with Pull-in and Hysteresis Phenomena," Sensors and Actuators A, 70, 56-60 (1998).

23. Bohm, S., W. Olthuis and P. Bergveld, "A Plastic Micropump Constructed with Conventional Techniques and Materials," Sensors and Actuators A, 77, 223-228 (1999).

24. Makino, E., T. Mitsuya and T. Shibata, "Fabrication of TiNi Shape Memory Micropump," Sensors and Actuators A, 88, 256-262 (2001).

25. Xu, D., L. Wang, G. Ding, Y. Zhou, A. Yu and B. Cai, "Characteristics and Fabrication of NiTi/Si Diaphragm Micropump," Sensors and Actuators A, 93, 87-92 (2001).

26. Culbertson, C., R. Ramsey and J. Ramsey, "Electroosmotically Induced Hydraulic Pumping on Microchips: Differential Ion Transport," Analytical Chemistry, 72 (10), 2285-2291 (2000).

27. Aston, C., "Biological Warfare Canaries," IEEE Spectrum, 38 (10), 35-40 (2001). 
ORNL/TM-2003/245

\section{INTERNAL DISTRIBUTION}

1. E. C. Fox

2. R. G. Gilliland

3-6. J. F. Jansen

7-10. L. J. Love

11-14. T. McKnight

15-18. T. Phelps
19-22: F. G. Pin

23-26. Yul Roh

27. Central Research Library

28. ORNL Laboratory Records RC

29-30. Laboratory Records OSTI

\section{EXTERNAL DISTRIBUTION}

(This document was cleared by DARPA and has been approved for Public Release, Distribution Unlimited)

31. V. Browning, DARPA/DSO, 3701 North Fairfax Dr., Arlington, VA 22203-1714 